\title{
Protoplast: A Valuable Toolbox to Investigate Plant Stress Perception and Response
}

\author{
Guillaume Gilliard ${ }^{1 \dagger}$, Eloïse Huby ${ }^{1,2 t}$, Sylvain Cordelier ${ }^{2}$, Marc Ongena ${ }^{3}$, \\ Sandrine Dhondt-Cordelier ${ }^{2 \ddagger \star}$ and Magali Deleu ${ }^{1 \neq *}$ \\ ${ }^{1}$ Laboratoire de Biophysique Moléculaire aux Interfaces, SFR Condorcet FR CNRS 3417, Gembloux Agro-Bio Tech, \\ Université de Liège, Gembloux, Belgium, ${ }^{2}$ RIBP EA 4707, USC INRAE 1488, SFR Condorcet FR CNRS 3417, Université de \\ Reims Champagne Ardenne, Reims, France, ${ }^{3}$ Microbial Processes and Interactions Laboratory, Terra Teaching and \\ Research Center, SFR Condorcet FR CNRS 3417, Gembloux Agro-Bio Tech, Université de Liège, Gembloux, Belgium
}

OPEN ACCESS

Edited by:

Marc Libault,

University of Nebraska-Lincoln,

United States

Reviewed by:

Nobuhiro Suzuki,

Sophia University, Japan

Jinxing Lin,

Beijing Forestry University, China

${ }^{*}$ Correspondence:

Sandrine Dhondt-Cordelier

sandrine.cordelier@univ-reims.fr

Magali Deleu

magali.deleu@uliege.be

tThese authors have contributed equally to this work and share first authorship

*These authors have contributed equally to this work and share last authorship

Specialty section:

This article was submitted to

Plant Cell Biology,

a section of the journa

Frontiers in Plant Science

Received: 29 July 2021 Accepted: 14 September 2021

Published: 05 October 2021

Citation:

Gilliard G, Huby E, Cordelier S, Ongena M, Dhondt-Cordelier $S$ and

Deleu M (2021) Protoplast: A

Valuable Toolbox to Investigate Plant Stress Perception and Response.

Front. Plant Sci. 12:749581.

doi: 10.3389/fpls.2021.749581
Plants are constantly facing abiotic and biotic stresses. To continue to thrive in their environment, they have developed many sophisticated mechanisms to perceive these stresses and provide an appropriate response. There are many ways to study these stress signals in plant, and among them, protoplasts appear to provide a unique experimental system. As plant cells devoid of cell wall, protoplasts allow observations at the individual cell level. They also offer a prime access to the plasma membrane and an original view on the inside of the cell. In this regard, protoplasts are particularly useful to address essential biological questions regarding stress response, such as protein signaling, ion fluxes, ROS production, and plasma membrane dynamics. Here, the tools associated with protoplasts to comprehend plant stress signaling are overviewed and their potential to decipher plant defense mechanisms is discussed.

Keywords: plant stress response, protein signaling, ion fluxes, cell membrane dynamics, plant protoplasts

\section{INTRODUCTION}

As sessile organisms, plants are exposed to myriads of potential stresses that can be harmful to their development. These adverse environmental conditions include both biotic and abiotic stresses that increasingly threaten agricultural plant productivity at a worldwide scale. In response, plants have developed an array of mechanisms to survive tough environmental conditions such as drought, heat, cold, nutrient deficiency, pollutants, pathogens, and herbivore attacks. The first crucial step in plant defense is the perception of the stress so that they can respond in a rapid and effective manner (Couto and Zipfel, 2016). While the underlying sensing mechanisms of abiotic stress are not fully elucidated, mostly due to functional redundancy in genes encoding sensor proteins or mutant lethality (Zhu, 2016; Gong et al., 2020), it is believed they are perceived by primary sensory mechanisms (Lamers et al., 2020). Several putative sensors have been ascribed to abiotic stresses perception and are often linked to membraneassociated proteins of the cells, organelles, or nucleus membrane proteins (Zhu, 2016). These sensors will then translate the changing environment into a signaling cascade allowing the plant to coordinate an appropriate response for acclimation. Similarly, plants have evolved an innate immune system to counteract the deleterious effects of biotic stresses (Jones and Dangl, 2006; Saijo and Loo, 2020; Zhou and Zhang, 2020). Once the constitutive plant defenses such 
as the cuticle, the cell wall (CW) and other physical and biochemical barriers are overrun, the plant plasma membrane $(\mathrm{PM})$ is then at the frontline of stress perception. Through cell surface and intracellular protein receptors, the plant is capable of sensing multiple molecular stress factors, such as MAMPs (microbe-associated molecular patterns), PAMPs (pathogen-associated molecular patterns), and DAMPs (damageassociated molecular patterns), thus initiating a cascade of signal transduction leading to a rapid and effective response from the plant (Cook et al., 2015; Couto and Zipfel, 2016). Both biotic and abiotic stresses share some early signaling events such as the production of reactive oxygen species (ROS) by NADPH oxidases, activation of protein kinases, receptors, or co-receptors through phosphorylation (Kadota et al., 2015; Yu et al., 2017; Zipfel and Oldroyd, 2017; Bigeard and Hirt, 2018), and rapid and transient change of ion fluxes (Jones and Dangl, 2006; Bigeard et al., 2015; Lamers et al., 2020). These fluxes can act on PM potential regulation and activation of $\mathrm{Ca}^{2+}$-dependent or $\mathrm{K}^{+}$-dependent enzymes (Jeworutzki et al., 2010; Bose et al., 2011; Demidchik, 2014; Wu et al., 2014b; Zipfel and Oldroyd, 2017; Sze and Chanroj, 2018; Yoshioka and Moeder, 2020). Then, activation of transcription factors (TFs) leads to the production of stress-related hormones such as abscisic acid, salicylic acid, jasmonic acid, and ethylene. Upon pathogen attacks, positive and negative crosstalks (Glazebrook, 2005) between these signaling molecules trigger the accumulation of an array of antimicrobial compounds such as pathogenesis-related proteins and phytoalexins (Delaunois et al., 2014).

How plants perceive and respond to these stress signals are essential biological questions and many of them are now investigated through innovative techniques that employ protoplasts as proxy for whole tissue, or even for whole plants. A protoplast refers to a spherical cell whose $\mathrm{CW}$ has been removed by digestive enzymes. The first protoplast isolations were developed in bacteria (Weibull, 1953) and fungi (Eddy and Williamson, 1957; Barbara and Bonner, 1959), before being transposed to plants (Cocking, 1960). They are usually obtained from enzymatic digestion of leaf and root tissues or even from cultured cells of a wide variety of species (Fowke et al., 1983; Yoo et al., 2007; Lin et al., 2018; Sangra et al., 2019; Zhao et al., 2019; Cheng and Nakata, 2020). With transformation methods already developed and microscopy techniques fast expending, the protoplast system could ultimately be considered as convenient screening platform to better target future whole plant analyses (Li et al., 2014). Moreover, freshly isolated mesophyll protoplasts are believed to retain the physiological properties of whole plants (Yoo et al., 2007).

Protoplasts have already been described as a useful and versatile system to study plant cell reprograming during development (Pasternak et al., 2020) and plastid transformation (Yu et al., 2020). In this review, we will focus on the different approaches and techniques that use protoplasts to study plant responses to both biotic and abiotic stresses and particularly on transient expression assays (TEA), on the use of fluorescence probes and on patch-clamp assays (Figure 1 for an overview). We will also enlighten and discuss the advantages and the limitations of protoplasts as a proxy for whole tissues or plants.

\section{PROTOPLASTS AS TOOLS IN BIOMOLECULAR STUDIES}

Protoplasts represent cell populations that are adapted for synchronous pharmacological and biochemical treatments and efficient genetic transformation (Sheen, 2001; Yoo et al., 2007; Xing and Wang, 2015). As TEAs in protoplasts can provide results in less than 36h (Yoo et al., 2007), they are a useful system to investigate early and transient events in plants during stress response at the biomolecular scale. TEAs are performed by isolating protoplasts from plant tissues, transfecting them in the presence of polyethylene glycol and calcium (Yoo et al., 2007; Lin et al., 2014) or through electroporation (Miao and Jiang, 2007) and incubating them for 2-24h. They have been developed in several plant species such as Arabidopsis thaliana (Asai et al., 2002; Boudsocq et al., 2004, 2010; Bethke et al., 2009; Li et al., 2019), maize (Kovtun et al., 1998), rice (Takai et al., 2007; Wang et al., 2014; Liu et al., 2018), barley (Saur et al., 2019), wheat (Hahn et al., 2020), strawberry (Gou et al., 2020), banana (Wu et al., 2020b), and rubber tree (Zhang et al., 2016). This system can be used for high-throughput analysis of plant signaling pathways and regulatory mechanisms (Figure 1).

\section{Functional Screening of Proteins}

Plant signaling involves several large protein families which contain many members. For example, in Arabidopsis, mitogenactivated protein kinase (MAPK), MAPK kinase (MAPKK), and MAPKK kinase families contain 20,10, and 60 members, respectively (Bigeard and Hirt, 2018), calcium-dependent protein kinase (CDPK) family has 34 members (Boudsocq et al., 2010), and TFs families such as MYB TFs, WRKY TFs, and basic leucine zipper transcription TFs comprise more than 176, 75, and 78 members, respectively (Dubos et al., 2010; Dröge-Laser et al., 2018; Wani et al., 2021). However, depending on the type of stress, the proteins involved in the signaling cascade may differ and a better understanding of plant defense mechanisms is therefore linked to the identification of its signaling components.

By avoiding time-consuming whole plant transformation, protoplasts offer a useful system to perform functional genomic screen among a group of proteins and determine which of them are able to activate defense genes. The screening is performed with reporter gene assay comprising a number of TEAs equal to the number of proteins or combination of proteins tested. In each TEA, protoplasts are transfected with 2 or 3 vectors simultaneously. One vector expresses the gene coding a protein of interest and has therefore a different sequence in each TEA. Then, a reporter gene often associated with a control gene, both constant between TEAs, can be expressed either in one (Hellens et al., 2005; Liu et al., 2018) or two different vectors (Asai et al., 2002; 


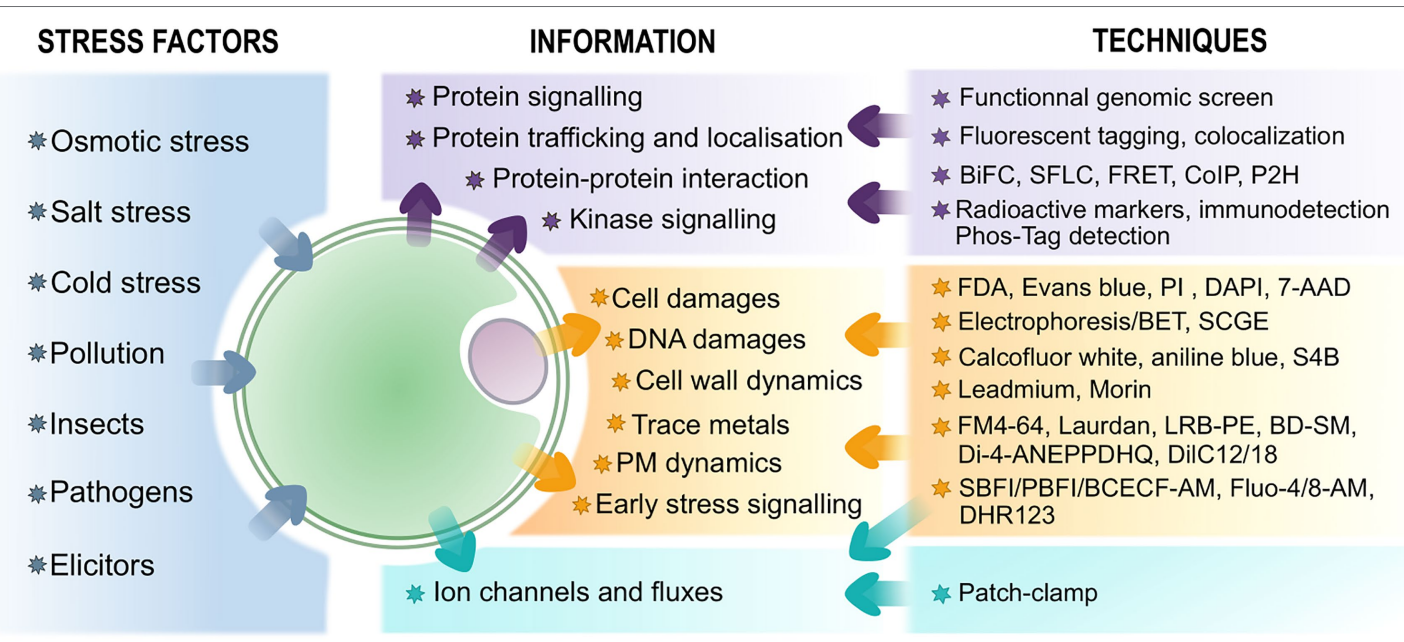

FIGURE 1 | Overview of techniques associated with protoplasts to study plant stress perception and response and the information they provide. The biomolecularrelated assays are in purple, fluorescence probes-associated techniques are in orange - see text for further information on the probes, and electrophysiological approaches are in blue.

Boudsocq et al., 2010). The reporter gene is under a stressinducible promoter that allows the detection of defense gene induction, while the control gene is under a constitutive promoter and allows the normalization of the reporter gene activity by taking into account experimental variation such as differences in cell number, in cell viability, and transformation efficiency (Kovtun et al., 1998). The firefly luciferase or the GFP gene is commonly used as reporter gene, while the B-glucuronidase (GUS) or the Renilla luciferase gene is often used as control gene (Kovtun et al., 1998; Sheen, 2001; Asai et al., 2002; Yoo et al., 2007; Wehner et al., 2011; Thévenin et al., 2012; Liu et al., 2018). The choice of the stress-inducible promoter represents the main limitation of the reporter gene assay as it has to be determined either based on the literature, or by detecting gene activation with PCR (Asai et al., 2002; Boudsocq et al., 2010; Chen et al., 2010). Finally, using the microtiter plate-based protoplast transactivation (PTA) system established by Wehner et al. (2011), high-throughput functional genomic screening can be performed to rapidly analyze up to 96 proteins.

Using this approach, screening of protein kinase families, such as MAPK and CDPK, and TFs has been performed to identify the one(s) involved in plant response to a specific biotic (Asai et al., 2002; Boudsocq et al., 2010; Sheikh et al., 2016) or abiotic stress (Chen et al., 2010; Wehner et al., 2011). When combined with RT-qPCR analysis, TEAs in protoplasts can also reveal potential synergic or antagonist effect between signaling pathways of signaling proteins (Asai et al., 2002; Boudsocq et al., 2010). Moreover, the use of vectors expressing structural variants of the protein of interest could evidence structural motifs compulsory for the signaling function of proteins (Mueller et al., 2012; Pecher et al., 2014). Such variants have provided clues on how allele selection plays a role in climate adaptation of some subspecies (Liu et al., 2018). Reporter gene assays in Arabidopsis protoplasts have also demonstrated the complex regulation between catalytic and regulatory subunit of sucrose non-fermenting1-related Kinase1 (SnRK1), involved in metabolic stress response and development (Ramon et al., 2019).

\section{Protein Location and Trafficking}

Besides the functional role of proteins in gene regulation, TEA can also provide information on their subcellular locations and dynamics (i.e., their mobility) into the cell when protoplasts are expressing both the studied protein fused with a fluorescent one, such as YFP, GFP, CFP, or mCherry, and a fluorescent marker specific of a cellular compartment. To that end, several markers have been developed to mark specifically plant organelles (Nelson et al., 2007; Zhang et al., 2021), and their diversity for the different organelles has been recently reviewed (Zhu et al., 2020). These information may help to elucidate protein function (Nelson et al., 2007), since TFs are expected to be found in the nucleus (Asai et al., 2002; Sheikh et al., 2016; Moon et al., 2019), protein receptors in the PM (Li et al., 2017; Liu et al., 2017; Pham et al., 2020), and proteins with a more versatile function can be found both in the cytosol and in cellular organelles (Boudsocq et al., 2010). Fluorescenttagged proteins in protoplasts have also been used to investigate the influence of the $\mathrm{CW}$ on PM protein dynamics (Daněk et al., 2020), the importance of membrane lipid composition in protein cell location (Nagano et al., 2016), and protein trafficking during signaling (Underwood et al., 2017; Menzel et al., 2019). TEA in protoplasts can also bring additional information on protein trafficking with secretion assays to identify and study vacuolar sorting receptor (daSilva et al., 2005; Shen et al., 2013) or signal peptide (Denecke et al., 1990) involved in the regulation of secretory pathways in plant.

\section{Detection of Protein-Protein Interaction}

The study of protein-protein interaction (PPI) through TEAs in protoplasts can also bring crucial information to decipher 
kinase signaling in plant cells (Pecher et al., 2014; Cheng et al., 2015; Liu et al., 2017; Ye et al., 2019; Li et al., 2020; Takahashi et al., 2020), the activation and interaction of TFs (Pecher et al., 2014; Liu et al., 2018; Ye et al., 2019), or even the interaction between immune receptors and co-receptors (Halter et al., 2014; Yeh et al., 2015; Fliegmann et al., 2016; Gong et al., 2019; Li et al., 2019).

The yeast two-hybrid ( $\mathrm{Y} 2 \mathrm{H})$ is a widely used high-throughput method to detect putative PPI and screen a broad range of interactions between proteins (Pecher et al., 2014; Wang et al., 2014; Liu et al., 2017, 2018; Gong et al., 2019; Ye et al., 2019). However, the physiology of the yeast cell differs from that of the plant cell. To get a system more representative of plant cell physiology, a protoplast two-hybrid ( $\mathrm{P} 2 \mathrm{H})$ system has been developed. This approach studies PPI by transferring the GAL4based two-hybrid system into plant protoplasts instead of yeast cells (Figure 2A; Ehlert et al., 2006; Iven et al., 2010). Hence, the P2H system identifies PPI between two proteins by fusing one of them with the binding domain (BD) and the second protein with the activation domain $(\mathrm{AD})$ of the transcriptional activator Gal4. With the use of GAL4-UAS4:GUS reporter plasmid, the PPI is detected when a higher GUS activity is observed. When studying interaction between leucine zipper TFs, this method was able to detect some weak interactions not detected in $\mathrm{Y} 2 \mathrm{H}$ system, suggesting that $\mathrm{P} 2 \mathrm{H}$ studies may be more representative of in planta conditions than $\mathrm{Y} 2 \mathrm{H}$ (Ehlert et al., 2006; Xing and Wang, 2015). P2H has also been used to analyze PPI involved in the regulation of heat shock response in Arabidopsis (Hsu et al., 2010) and in auxin signaling in tobacco (Böttner et al., 2009). Furthermore, in a similar way as it was developed for functional genomic screening, a highthroughput PPI screening can be performed with the combination of P2H and a microtiter plate-based system (Wehner et al., 2011).

Nevertheless, since both $\mathrm{Y} 2 \mathrm{H}$ and $\mathrm{P} 2 \mathrm{H}$ studies are performed in the nucleus, they are therefore possibly limited to specific classes of proteins such as TFs (Ehlert et al., 2006) and complementary approaches using TEA in protoplasts should be considered to confirm PPI in planta. These additional techniques comprise co-immunoprecipitation assays (co-IP; Figure 2B; Li et al., 2019; Ye et al., 2019), protein complementation assays (PCA), including bimolecular fluorescence complementation (BiFC; Pecher et al., 2014; Liu et al., 2018; Takahashi et al., 2020; Yang et al., 2020) and split luciferase complementation (SLC; Figure 2C; Cheng et al., 2015; Gong et al., 2019) and Förster Resonance Energy Transfer (FRET) experiments (Figure 2D; Halter et al., 2014; Fliegmann et al., 2016).

To study PPI with co-IP (Figure 2B), protoplasts are transformed with two vectors, each containing one of the proteins of interest fused with a different epitope, such as the hemagglutinin (HA) tag or the FLAG tag (Cheng et al., 2015; Li et al., 2019). The protoplasts are then lysed, and the proteins are immunoprecipitated using one of the two epitopes. The resulting extract is then analyzed by western blot to detect the second epitope and confirm the PPI. This approach has been used in Arabidopsis protoplasts to demonstrate the association of the receptor-like kinase (RLK) BAK1 with a calcium channel when studying plant cell death (Yu et al., 2019). Still in Arabidopsis, it highlighted the negative effect of the RLK NIK1, involved in antiviral immunity, on bacterial immunity by showing its impact on the formation of the complex between FLS2 and its co-receptor BAK1, paramount in the sensing of the bacterial PAMP flagellin22 (flg22; Li et al., 2019). Co-IP experiments on protoplasts also evidenced the importance of ubiquitination of another RLK, BIK1, for plant immune response regulation (Ma et al., 2020). Nevertheless, co-IP does not provide spatial nor temporal information on PPI. Besides, it is an in vitro approach and the lysis process may disrupt weak interaction or induce interaction between proteins that would never be brought together under physiological conditions (Struk et al., 2019). Hence, if the PPI studied is transient, other in vivo approaches should be considered such as PCA or FRET (Cui et al., 2019; Struk et al., 2019; Takahashi et al., 2020).

In PCA (Figure 2C), one of the studied proteins is fused with the amino-terminal part and the other one with the carboxy-terminal part of a fluorescent protein, such as YFP or mCherry, for BiFC (Pecher et al., 2014; Cheng et al., 2015; Li et al., 2020) or a luciferase enzyme, such as the firefly luciferase, for SLC (Chen et al., 2008; Cheng et al., 2015; Gong et al., 2019). In BiFC, when the two proteins interact, the combination of the two parts of the fluorescent protein restores the fluorescence enabling the visualization and the spatial location of protein complexes. In SLC, the interaction of the two proteins restores the luciferase activity which can be detected in the presence of luciferin by the measurement of chemiluminescence. Thanks to PCA on protoplasts, information on in vivo PPI can be obtained, but both techniques have their specificities. With BiFC, the location of both longstanding and transient PPI can be observed, while the high background signal observed with SLC prevents such observation (Fujikawa and Kato, 2007; Cui et al., 2019). In Arabidopsis, BiFC has shown the PM location of the interaction between proteins involved in stress response. For instance, it evidenced the interplay between the ATP-recognition receptor DORN1 and the NADPH oxidase RBOHD, involved in ROS production and stomatal closure (Chen et al., 2017). It also showed the nitrate-sensing mechanism where transceptor NRT1.1, that acts as nitrate transporter and sensor, interacts with the calcium channel CNGC15 (Wang et al., 2021). However, the irreversible recombination of fluorescent proteins used in BiFC limits its ability to study PPI dynamics and SLC offers a better alternative in that regard (Kerppola, 2006; Kudla and Bock, 2016; Cui et al., 2019; Struk et al., 2019). Indeed, the reversibility of luciferase recombination allows detection of both the association and dissociation of two proteins in less than $1 \mathrm{~min}$ following treatment (Li et al., 2011; Wang et al., 2020b).

Another way to study PPI dynamics and location in vivo with protoplasts is the use of FRET. Here, two putative interacting partners are fused with a fluorophore (Halter et al., 2014; Fliegmann et al., 2016; Rios et al., 2017; Long et al., 2018). One partner is fused with a donor fluorophore, while an acceptor fluorophore is fused to the putative interacting partner (Figure 2D). The donor fluorophore displays an 


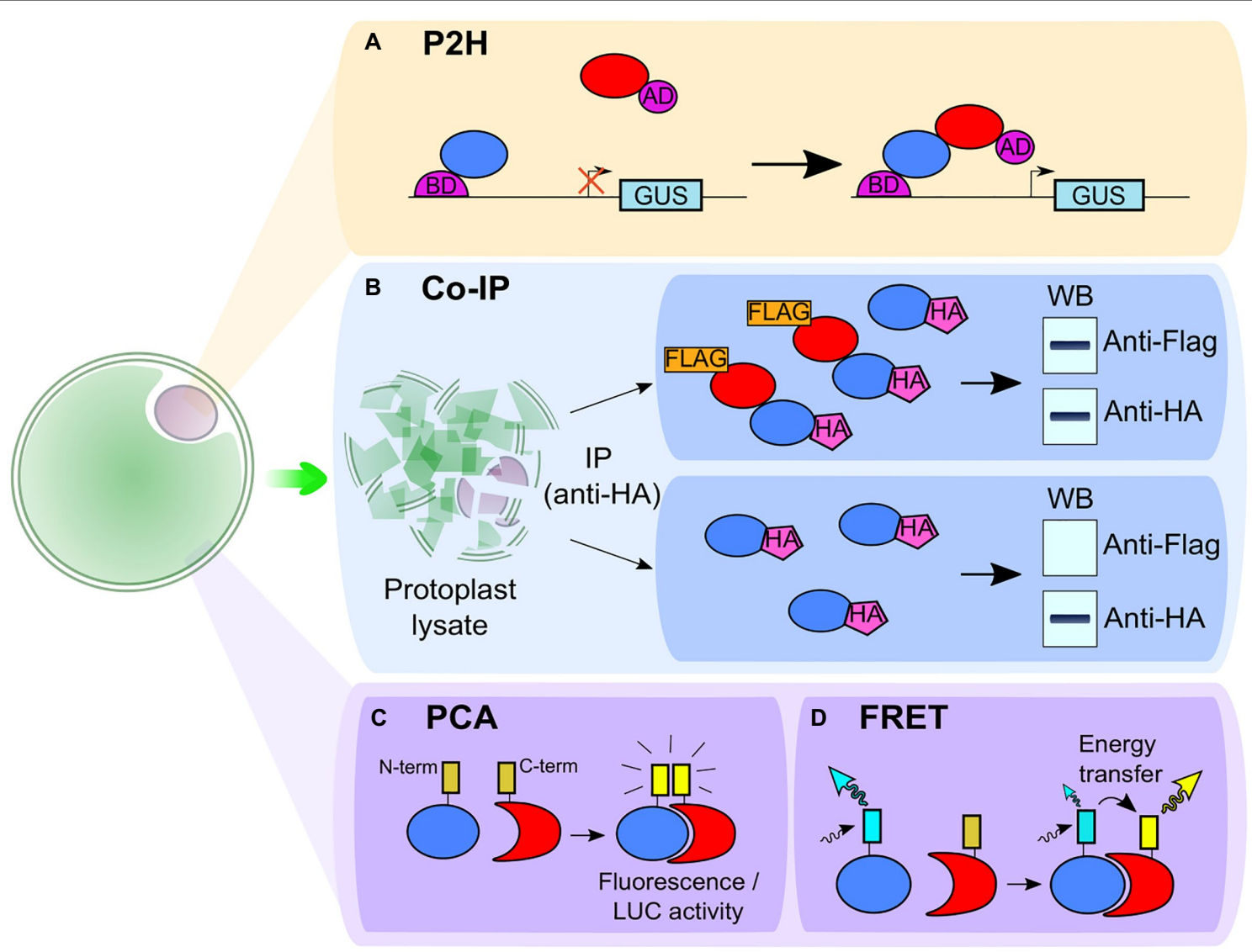

FIGURE 2 | Schematic representation of techniques associated with protoplasts to study protein-protein interaction. (A) In the protoplast two-hybrid (P2H) system, the protoplasts are transformed with the GAL4-UAS4:GUS reporter plasmid and the two putative interacting partners are fused to the binding domain (BD) and the activation domain (AD) of the transcriptional activator Gal4. An interaction between the partners leads to the transcription of the glucuronidase (GUS) gene and to a higher GUS activity. (B) In co-immunoprecipitation (co-IP), the two putative interacting partners are fused to two different epitopes [e.g., hemagglutinin (HA)-tag and FLAG-tag]. The proteins are then extracted from protoplast lysate with a co-IP using one of the two tags (here, the HA-tag). If the proteins are interacting, both HAtagged and FLAG-tagged proteins are extracted which can be observed with a western blot (WB; upper box). If the proteins do not interact, only the HA-tag is detected in the western blot (bottom box). (C) In protein complementation assay (PCA), such as bimolecular fluorescence complementation (BiFC) or split luciferase complementation (SLC) assay, two fragments (the carboxy-terminal and the amino-terminal parts) of a reporter protein are fused to two putative interacting partners. In BiFC, the fragments come from a fluorescent protein and in SLC, from a luciferase enzyme. The interaction between partners leads to the association between the $\mathrm{N}$ - and C-ter fragments and restores fluorescence (for BiFC) or luciferase activity detected in the presence of luciferin (for SLC). (D) In Förster Resonance Energy Transfer (FRET), each of the two putative interacting partners is fused with one different fluorophore, either a donor or an acceptor. When the partners are interacting, the donor can transfer its energy of excitation to the acceptor, inducing a change in fluorescence intensity of the fluorophores and in the fluorescence lifetime of the donor.

emission spectrum that overlaps with the excitation spectrum of the acceptor fluorophore. When the proteins interact, it brings the donor in close proximity to the acceptor allowing a transfer of energy from the first fluorophore to the second. This leads to a decrease in fluorescence intensity and lifetime of the donor concomitant with an increase in fluorescence intensity of the acceptor. As FRET is based on a remote interaction and not a physical interaction between the tags of the proteins of interest, this approach allows the study of PPI dynamics with information on protein location. It has, for instance, been used in Arabidopsis protoplasts to show the early disruption of the interaction between the ethylene factor ERF104 and MAPK6 following treatment with flg22 (Bethke et al., 2009). The implementation of FRET analysis first requires an optimization of the labeling condition. In this regard, TEAs in protoplast represent a convenient tool to test a large number of FRET pair combinations before transposing it to whole plants or tissues (Long et al., 2018). Nevertheless, FRET measurements require a high accumulation level of the protein of interest and advanced equipment to detect the signal, explaining its limited use in PPI studies (Cui et al., 2019; Struk et al., 2019).

In summary, TEAs in protoplasts associated with the aforementioned techniques provide useful tools to study PPI in plant cells. Each technique has its own characteristics and limitations hence why a complementary use of several of them should be envisaged to get a reliable and comprehensive view of PPI. PPI studies are, however, not restricted to protoplasts, and readers interested in PPI analysis in other systems may refer to recent reviews (Cui et al., 2019; Struk et al., 2019). 


\section{Detection of Kinase Activity and Protein Phosphorylation}

Following the identification of PPI, one could be interested in understanding its consequences, such as the activation of kinases or protein phosphorylation. To that end, crude or immunoprecipitated protein extracts are collected from lysates of protoplasts or plant seedlings having undergone biotic or abiotic stress. Compared to experiments in plant seedlings which require mutant generation, protoplasts transiently expressing the studied protein(s) provide a high-throughput system to perform explorations as well as hypothesis-driven tests as results can be obtained in a few days (Yoo et al., 2007). For instance, Arabidopsis protoplasts have been used to study flg22-induced phosphorylation of the RLK BIK1 (Li et al., 2019) and investigate the importance of amino acid residue for protein phosphorylation in PAMPs-triggered immunity (Menzel et al., 2019) and in cold stress (Ye et al., 2019). The assessment of kinase activation is then performed either by the detection of the kinase activity through the phosphorylation of kinase substrate or by detecting phosphorylated kinases as their activation is linked to their phosphorylation state.

To detect kinase substrate phosphorylation, proteins extracted from protoplasts are incubated with the radioactive marker $\gamma\left[{ }^{32} \mathrm{P}\right] \mathrm{ATP}$ and a substrate, which can be a protein, such as a histone of myelin basic (Asai et al., 2002; Boudsocq et al., 2004, 2010; Liu et al., 2017), a kinase, such as MAPK for MAPKK (Asai et al., 2002; Wang et al., 2014), or even a lipid (Menzel et al., 2019). Once incubated, the kinase activity is determined by measuring the incorporation of the radioactive marker into the kinase substrate. To avoid the use of radioisotopes, an alternative method to measure the phosphorylation of kinase substrate has been developed using a phosphate-binding tag (Phos-Tag) assay (see below; Kinoshita et al., 2006).

Finally, protein phosphorylation can be detected either with specific antibody or by observing mobility shift of proteins with SDS-PAGE (Pecher et al., 2014; Li et al., 2019; Yu et al., 2019; Ma et al., 2020). To perform immunodetection, crude protein extract is analyzed by western blot with a primary antibody recognizing phosphorylated amino acids (Gong et al., 2019; Li et al., 2019) or motifs such as dual phosphorylation specific to active MAPKs detected with anti-pERK antibody (Cheng et al., 2015; Zhang et al., 2016; Gong et al., 2019). For the mobility shift assay, Phos-Tag can be added into the SDS-gel to improve the separation between non-phosphorylated and phosphorylated proteins (Kinoshita et al., 2006; KinoshitaKikuta et al., 2007; Bekesová et al., 2015). Thanks to protoplastassociated Phos-Tag mobility shift assay, the phosphorylation of kinases (Bi et al., 2018; Menzel et al., 2019), TFs (Ye et al., 2019), or other proteins (Liu et al., 2017) involved in the signaling process in biotic and abiotic stress has been detected. Hence, while being an alternative to radioisotopes, Phos-Tag assays are also a suitable alternative to antibody recognizing phosphorylated proteins, which are costly or even not always commercially available, to detect protein phosphorylation and kinase activation (Bekesová et al., 2015; Kinoshita et al., 2015). Finally, to confirm that the mobility shift observed is due to phosphorylation, treatment with phosphatase to abrogate the mobility shift is often performed (Pecher et al., 2014; Liu et al., 2017; Bi et al., 2018; Li et al., 2019). Additionally, TEA in protoplasts can also provide information on the consequence of phosphorylation such as the degradation of calcium channels (Yu et al., 2019) or TFs that regulate stress-related genes (Sheikh et al., 2016; Liu et al., 2017).

\section{Complementarity of Biomolecular Assays Performed on Protoplasts and Whole Cells}

As presented above, many biomolecular assays have been developed with protoplasts to decipher plant signaling mechanisms in biotic or abiotic stress conditions. All these different types of assays offer a useful toolbox to analyze plant responses and get new insights to better understand the signaling cascade in plants, starting from the perception by a protein receptor to the activation of TFs and genes, passing by the kinase signaling cascade.

The use of these tools is not restricted to protoplasts, and TEA can be performed directly in plant tissues using particle bombardment or Agrobacterium infiltration (Cheng et al., 2015; Liu et al., 2017, 2018; Bi et al., 2018; Pham et al., 2020; Takahashi et al., 2020). The latter is used either to transform only specific plant tissue or to produce transgenic plant lines constitutively expressing the gene of interest (Wu et al., 2014a; Sharma et al., 2018). Nevertheless, all these approaches present advantages and limitations. Therefore, TEAs performed in protoplasts are complementary to TEAs performed in intact plant tissues and constitutive expression in mutant plants (Denecke et al., 2012; Sharma et al., 2018). Indeed, protoplasts are obtained from the digestion of tissues containing a mixture of differentiated cell types that can display different locations of specific proteins (Faraco et al., 2011). Even though some protocols exist to isolate protoplasts of specific cell types such as guard cell (Zhao et al., 2019), aleurone layer cell (DaneriCastro and Roberts, 2016), or from various root tissues (Demidchik et al., 2003), the complementary use of transgenic plants is recommended if a tissue-specific behavior of the process studied is anticipated (Sharma et al., 2018). Instead, if no tissue-specificity is expected, protoplasts offer a valuable model to study physiological processes as it is less timeconsuming to obtain than transgenic plant and can be performed in a broad range of plant species, contrary to agroinfiltration in leaves that are mainly restricted to the plant host Nicotiana benthamiana (Sharma et al., 2018). Furthermore, in agroinfiltration experiments, the moment when the gene transfer occurs is not well defined. On the contrary, with protoplasts transformation, the moment where the DNA transfer happens is well known and gene products can be detected as early as $4 \mathrm{~h}$ after gene transfer (Denecke et al., 2012). Hence, protoplasts are a useful system to perform time-course experiment of gene expression (Babu et al., 2008), which are more difficult to carry out in infiltrated cells (Denecke et al., 2012).

Even though TEA in protoplasts or intact cells can bring precious findings, some cautions must be taken when using these tools. The experiment must be carefully designed to avoid 
overexpression artifacts which can lead to artificial cytosolic location, or even aggregation of the protein (Sharma et al., 2018). This can be done by adapting the amount of DNA plasmid used for transformation or the incubation time of protoplasts for gene expression, usually less than $24 \mathrm{~h}$, to obtain low-expressing protoplasts for experimental purpose (Yoo et al., 2007; Denecke et al., 2012). Moreover, the enzymatic CW digestion performed to isolate protoplasts may stress the cell which could alter the expression levels of some genes (Birnbaum et al., 2003; Takai et al., 2007; Jeworutzki et al., 2010). As an example, in a screen of more than 22,000 Arabidopsis genes, 356 were found to be induced at least twice more by the CW digestion (Birnbaum et al., 2003) and some flagellin-inducible genes have also shown higher expression following protoplast isolation in rice (Takai et al., 2007). Such induction of genes in protoplasts may alter cell responses to stimulus such as the activation of ion channels (Jeworutzki et al., 2010). In addition to altered gene expression, protoplast isolation can change the sensitivity of cell enzymes to its inhibitor, as shown for phosphoenolpyruvate carboxylase regarding malate inhibition (Petropoulou et al., 1990). It is therefore important to assess that the biological response in protoplasts is not disturbed compared to intact plant cells. Gene induction or protein accumulation similar to whole plants levels (Asai et al., 2002; Boudsocq et al., 2004; Underwood et al., 2017) and the verification with fluorescent probes of protoplast integrity are possible controls.

\section{THE VERSATILITY OF FLUORESCENT PROBES ON PROTOPLASTS}

With the advent of cell imaging technologies, fluorescence microscopy has been increasingly used for the visual insight it provides. While many probes can be used on plant tissues, autofluorescence and probe specificity have turned out to be an issue. Some dyes also tend to accumulate within the $\mathrm{CW}$ microfibrils, tempering with the imaging process (Blachutzik et al., 2012). Fluorescent probes applications on protoplasts appear then as particularly useful since they allow observations at the single cell level without the issues caused by the presence of the CW (Figure 1 for an overview).

\section{Cell Viability and DNA Damages}

Fluorochromes are often used to discriminate between living and dead protoplasts and to assess their viability and the damages they might have suffered. Indeed, protoplast isolation procedures and the culture conditions that follow, may induce cell stress or damage (Neelakandan and Wang, 2012), which should be avoided if one wants to study the effect of biotic and abiotic stresses. One of the most referenced dyes is FDA (fluorescein diacetate), which highlights living cells (Bertini et al., 2019; Sangra et al., 2019; Qiu et al., 2020) or Evan's blue, which highlights dead ones (Kollárová et al., 2019). Other fluorochromes can be used, such as PI (propidium iodide), DAPI (4'6-diamidino-2-phenylindole, dichloride), and 7-AAD (7-amino-actinomycin D) that do not cross intact PMs. Issues have previously been raised regarding techniques using fluorescence microscopy, as the quantification is linked to the viewer's perception of fluorescence (Aoyagi, 2011; Badaró Costa et al., 2018). Thus, new automated measurements, such as flow cytometry (FCM; Zhou et al., 2019; González-García et al., 2020) and Muse cell analyzer, a compact FCM, allowing screening and sorting of protoplasts, along with measures on smaller volumes have been developed (Badaró Costa et al., 2018).

DNA damage evaluation is another frequently employed marker to assess protoplast viability or the effect of genotoxicity of environmental pollutants and abiotic stresses on protoplasts. In these procedures, protoplasts are used as a direct source of nuclei to perform gel electrophoresis with ethidium bromide staining in order to detect DNA laddering (Poot-Poot et al., 2016). Identically, single cell gel electrophoresis assay (SCGE), also called Comet assay, allows the study of DNA damage on protoplasts at the single cell or nuclei level (Kuzminsky et al., 2016; Badaró Costa et al., 2018; Choury et al., 2018). While this technique is amply used on animal cell cultures which are easily lysed, the presence of the CW makes it technically difficult to transpose on plant tissue or cell culture. Hence, nuclei isolation through protoplast formation or mechanical destruction of the CW is here preferred (Gichner et al., 2009; Santos et al., 2015; Choury et al., 2018). Finally, DAPI, which has a high affinity for DNA double strand, has also been used to study apoptosis-like cell death and more specifically chromatin condensation and DNA fragmentation in Brassica napus leaves (Watanabe et al., 2002).

\section{Cell Wall Dynamics}

The CW has a direct role at the frontline of plant defense along with other chemical and physical barriers such as waxes, hairs, and secondary metabolites (Malinovsky, 2014; Engelsdorf et al., 2018). It also possesses an indirect role in plant defense systems, as during a pathogen invasion, cell wall integrity can be modified, parts of the $\mathrm{CW}$ can be broken down and their fragments (referenced as DAMPs) can activate plant immune responses (Souza et al., 2020). As protoplasts are cells deprived of CW, they offer a unique point of view on the complete de novo synthesis of the $\mathrm{CW}$ by providing an excellent support for visualizing its regeneration dynamics and characterizing the cellular proteins involved in the process (Yokoyama et al., 2016). Although changes in CW composition are often studied through biochemical analyses, histochemical staining with fluorochromes is increasingly used to bring a visual insight on these changes. For instance, calcofluor white is employed to preferentially stain cellulose and aniline blue to stain callose (Yokoyama et al., 2016; Kollárová et al., 2019). Using these probes, it has, for instance, been demonstrated that when cultivated in stressful conditions, cellulose microfibrils were not deposited on the surface of white birch protoplasts and only callose deposition could be observed (Tagawa and Kondo, 2018; Tagawa et al., 2019). Calcofluor white has also been used to study the deleterious effect of cadmium on maize protoplast CW regeneration (Kollárová et al., 2019). Another 
method also emerged using S4B (Pontamine Fast Scarlet 4 BS) in combination with spinning disk confocal microscopy to stain cellulose patterning on living cells. As calcofluor has toxic properties that might injure cells, this method appears to be more suited to real-time imaging of living protoplasts (Anderson et al., 2010; Yokoyama et al., 2016; Kuki et al., 2017).

Similarly, CW components and callose deposition are known to block the migration of trace metals within cells, such as aluminum which binds to calcium pectate in the CW (Lee et al., 2001). Therefore, protoplasts are often combined with specific fluorochromes to study the effects and uptake of trace metals directly on cells (Krzesłowska, 2011). For instance, Leadmium was used to visualize the uptake of cadmium by protoplasts and its deleterious effects on $\mathrm{CW}$ regeneration of wheat (Greger et al., 2016) and maize (Kollárová et al., 2019). Similarly, morin was used to study aluminum toxicity on coffee protoplasts, along with DAPI to monitor its localization into their nuclei (Poot-Poot et al., 2016). It was also used to examine its toxicity on root protoplasts of transgenic camelina (Park et al., 2017).

\section{Plasma Membrane Dynamics}

Along with the CW, the PM also plays a major role in plant resistance to both biotic and abiotic stresses. Whether it is by regulation of ion exchanges, perception of PAMPs/MAMPs/ DAMPs, or signal transduction, both lipids and proteins of the PM are key players in its physiological function (Lim et al., 2017; Mamode Cassim et al., 2019; Schellenberger et al., 2019; Huby et al., 2020; Saijo and Loo, 2020). Moreover, following the CW, the PM is the first point of contact between plant cells and pathogens and many proteins involved in plant defense are embedded in it. More specifically, the dynamic between membrane microdomains, which are highly ordered domains rich in sphingolipids and sterols, and the stress-related proteins they harbor is crucial for immunity (Gronnier et al., 2016, 2018; Nagano et al., 2016; Mamode Cassim et al., 2019; Huby et al., 2020).

The absence of $\mathrm{CW}$ makes possible the accurate visualization of events at the protoplast PM using fluorescent probes. However, while a lot of probes exist to study lipid organization and dynamics into artificial model membranes which are deprived of proteins, they often cannot be directly applied to living cell and protoplast PMs which are far more complex and require deep protocol adaptations in terms of concentration and incubation time (Klymchenko and Kreder, 2014). Every probe will have its specificities and are used by themselves or combined. For instance, FM4-64 [N-(3-Triethylammoniumpropyl)-4-(6-(4(Diethylamino) Phenyl) Hexatrienyl) Pyridinium Dibromide] and LRB-PE (Lissamine Rhodamine B-Phosphoethanolamine) have been employed to specifically stain phospholipid enriched areas of protoplast PM and BD-SM (Bodipy Sphingomyelin $\mathrm{FL} \mathrm{C}_{12}$ ) has been used to stain sphingolipid enriched domains (Blachutzik et al., 2012). FM4-64 and BD-SM were also used in combination with FRAP (fluorescence recovery after photobleaching) experiments to visualize lipid redistribution. The identification of ordered and disordered regions of the
PM is also possible with the solvatochromic dyes di-4ANEPPDHQ and laurdan that show a shift in emission wavelength when lipids undergo phase transition from gel to fluid state (Blachutzik et al., 2012; Klymchenko, 2017). Di-4ANEPPDHQ has notably been used on protoplasts from rice transgenic plants that lack fatty acid hydroxylase 1 and 2 (FAH1/2), enzymes responsible for the formation of 2-hydroxy sphingolipids (2-OH-SL), precursors of glycosylinositol phosphorylceramides (GIPC), that are both located at the PM in Arabidopsis. They demonstrated that a disordered PM was concomitant with a lower amount of $2-\mathrm{OH}-\mathrm{SL}$ which gave rise to an increased sensibility to rice blast fungus infection (Nagano et al., 2016). Di-4-ANEPPDHQ has also been used in Arabidopsis FAH1/2 mutants, to show a lower order of the PM compared to the wild type, suggesting an altered PM organization when its content in GIPC is low (Lenarčič et al., 2017).

While there are many advantages to use fluorescent probes directly on protoplasts, its PM remains an active, dynamic structure, which can cause issues. It has been reported that some probes could be internalized in the cytoplasm, such as DiIC12 (1,1'-Didodecyl-3,3,3',3'-Tetramethylindocarbocyanine Perchlorate) and DiIC18 (1,1'-Dioctadecyl-3,3,3',3'Tetramethylindodicarbocyanine-5,5'-Disulfonic Acid), which stains phospholipids, leading to a decrease in fluorescence in the PM (Blachutzik et al., 2012). By using calcofluor and di-4ANEPPDHQ on tobacco protoplasts, it has been shown that the absence of a CW does not affect the organization of PM-ordered domains (Grosjean et al., 2018), suggesting that the PM microdomain functions of a protoplast remain highly similar to that of an intact tissue. However, in Arabidopsis, FRAP analysis proved that the removal of the $\mathrm{CW}$ increased the overall dynamics and mobility of the PM proteins (Martinière et al., 2012), including proteins involved in response to extracellular stimuli flotilin2 proteins (AtFLOT2) and hypersensitive induced reaction proteins (AtHIR1; Daněk et al., 2020).

\section{Detection of Early Stress Signaling Events}

Fluorescent probes can also be useful to detect specific early stress signaling events like ROS production and ions fluxes. For instance, in Arabidopsis, the molecular probe ContPY1 was used to detect the intracellular accumulation of a ROS, hydrogen peroxide $\left(\mathrm{H}_{2} \mathrm{O}_{2}\right)$ in response to the elicitor COS-OGA. The comparison between protoplasts and cell suspensions evidenced the relative contribution of $\mathrm{CW}$ peroxidases and membrane dehydrogenases to $\mathrm{H}_{2} \mathrm{O}_{2}$ production (Ledoux et al., 2014). On maize, the Amplex red reagent, which reacts with $\mathrm{H}_{2} \mathrm{O}_{2}$ to produce the highly fluorescent resorufin, and the rhodamine dye DHR123 (Dihydrorhodamine 123) were used to measure ROS in both organelles and protoplasts and link their quantities to DNA damage in developing mitochondria and plastids (Tripathi et al., 2020).

Similarly to ROS production, ion fluxes can be easily studied with fluorescent probes associated with protoplasts. For instance, $\mathrm{K}^{+}$efflux was monitored with the fluorescent probe PBFI-AM 
(Potassium-Binding Benzofuran Isophthalate Acetoxymethyl ester) and cytosol acidification with the $\mathrm{pH}$-sensitive probe BCECFAM [2',7-Bis-(2-Caboxyethyl)-5-(and-6)-Carboxyfluorescein Acetoxymethyl ester] in wheat and rice protoplasts to study anoxia-induced events (Yemelyanov et al., 2020). Furthermore, protoplasts loaded with the probe SBFI-AM (Sodium Binding Benzofuran Isophthalate Acetoxymethyl ester) were used to study salt stress on wheat. They helped to demonstrate that the application of a moderate amount of $\mathrm{K}^{+}$was concomitant with a decrease in cytosolic $\mathrm{Na}^{+}$alleviating its toxic effects on cells (Gul et al., 2019). Regarding $\mathrm{Ca}^{2+}$ fluxes, their induction has been monitored in elicited protoplasts expressing the genetically encoded reporter system aequorin, a bioluminescent protein (Maintz et al., 2014). This technique can, however, be lengthy, especially for slow growing plants such as fruit trees since it requires plant transformation (Qiu et al., 2020). So small dyes like fluo-8/AM, fluo-4/AM (fluo-8/4 acetoxymethylester) and rhod-2/AM (rhod-2 acetoxymethylester) can be preferred. These molecules are flexible, rapid, and non-cytotoxic. They have been used for calcium imaging on protoplasts of "Fuji" apples (Qiu et al., 2020). Fluo-4/AM has also been used with FCM and confocal microscopy on rice protoplasts to evaluate ceramide-induced programmed cell death (Zhang et al., 2020). While there are many advantages to fluorescent probes to study ion fluxes in protoplasts, there are still some limitations such as the commercial availability of probe sensitive to anions.

\section{PROTOPLASTS AND PATCH-CLAMP ELECTROPHYSIOLOGY}

Complementary to fluorescent probes, plant ion fluxes can be studied using patch-clamp electrophysiology that measures ion currents flowing through a membrane (Demidchik et al., 2006; Elzenga, 2012). This technique is a powerful tool to identify and characterize ion channel and non-channel proteins, such as $\mathrm{H}^{+}$-ATPases, present in biological membranes (Demidchik et al., 2006; Elzenga, 2012; Hamilton et al., 2015). To measure the ionic current with patch clamp, a high resistance contact, the so-called gigaOhm seal, has to be performed between a glass micropipette and a patch of a membrane containing the ion transporter of interest (Demidchik et al., 2006; Elzenga, 2012). The access to a CW-deprived plant cell is particularly important to measure PM ionic current (Elzenga, 2012). Hence, protoplasts are the model of choice to perform patch-clamp electrophysiology on plant.

Four patch-clamp configurations exist, and readers interested in this technique may refer to previous reviews for more details on their specificities (Demidchik et al., 2006; Elzenga, 2012). This technique has provided important insights in the understanding of anion channels involved in immunity (Zheng et al., 2018; Chan et al., 2020) and ABA signaling during osmotic stress (Takahashi et al., 2020). It also contributed to a better comprehension of mechanoperception in plant (Nakagawa et al., 2007; Haswell et al., 2008), potassium and calcium fluxes involved in salt stress (Fuchs et al., 2005; Liya et al., 2012).
It also helped to elucidate calcium fluxes involved in $\mathrm{H}_{2} \mathrm{O}_{2}$ perception (Demidchik et al., 2007; Tian et al., 2019; Wu et al., 2020a), in extracellular ATP perception (Demidchik et al., 2009), in cold stress (Carpaneto et al., 2007), and in stomatal immunity (Yekondi et al., 2018).

Patch-clamp electrophysiology is the gold standard technique to study ion channels and fluxes even though the process to isolate the cell and remove its CW can be considered a limitation (Demidchik et al., 2006; Hamilton et al., 2015). However, combination of patch clamp with other electrophysiological or physiological techniques using intact plants such as microelectrode ion flux estimation or the use of fluorescent probes can be considered to improve the robustness of the results (Demidchik et al., 2006; Hamilton et al., 2015; Demidchik, 2018).

\section{CHALLENGES AND FUTURE PERSPECTIVES}

The current and upcoming rise of pests, diseases, and changes of agricultural practices caused by environmental perturbations will put an increasing pressure on agricultural productivity. This will require specific tools allowing fast, high throughput, or even automated systems, to provide reliable and efficient solutions for crop and genetic engineering.

With the advent of quick and reliable transformation and microscopy methods, protoplasts arise as useful and powerful tools for a wide range of stress-related studies (Figure 1). We have argued in this review that the use of protoplasts could turn out to be both an advantage and a limitation (Figure 3). While it has been previously stated that protoplasts maintain a similar physiological cellular activity to whole plants (Sheen, 2001; Wang et al., 2020a; Shaw et al., 2021), they ultimately serve as proxy to whole plants studies, implying that complementary experiments are often necessary to connect the phenomena observed on protoplasts to plants. Nonetheless, the single cell level allows for specific, rapid, and high-throughput analysis along with time-course experiments. In addition, even though protoplasts isolation and maintenance require specific conditions that can eventually cause stress, these techniques are improving for a wide range of species or organs (Sangra et al., 2019; Shan et al., 2019; Davis et al., 2020). Furthermore, their formation is still deemed necessary to bypass timeconsuming plant culture and whole plant transformation, especially for recalcitrant species or plants with a long reproductive cycle (Du and Bao, 2005). Moreover, somatic hybridization mediated by protoplast fusion has been employed to circumvent sexual incompatibility encountered in plant breeding (Watanabe et al., 2002; Du and Bao, 2005).

Protoplasts possess multiple assets for the upcoming challenges in plant biology. Many technologies employing them are being developed, and these techniques could ultimately facilitate plant stress-related studies. For instance, protoplasts have been employed to assess the efficiency of CRISPR-associated protein 9 (Cas9) mutagenesis, bypassing or preceding stable transformation which can be time-consuming (Lin et al., 2018; 


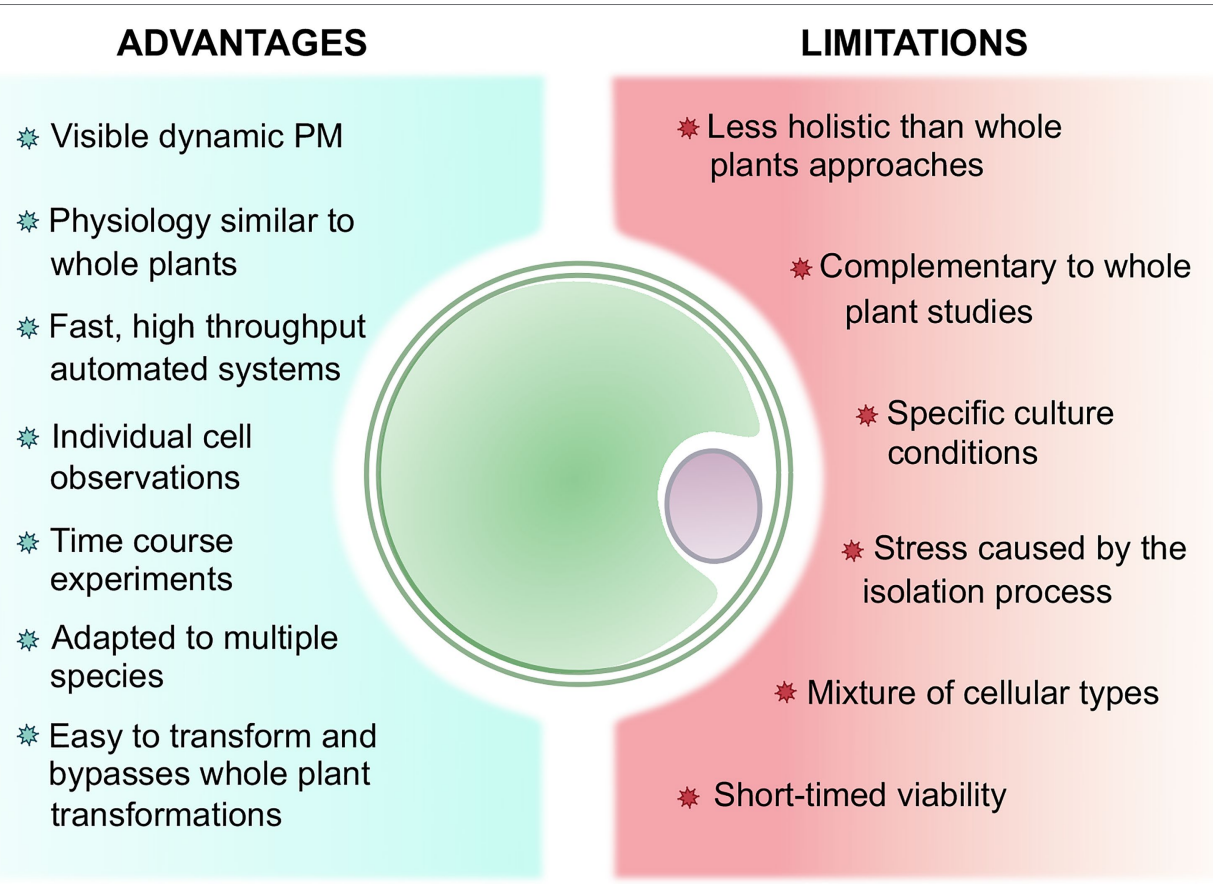

FIGURE 3 | Summary of the advantages and limitations of working with protoplasts to study plant stress perception and response comparatively to whole plants.

Hahn et al., 2020; Guyon-Debast et al., 2021; Nicolia et al., 2021). Another example is the adaptation of efficient and low-cost microfluidic techniques to perform spatiotemporal studies of plant protoplasts physiology during their development (Sakai et al., 2019) and to apprehend the electrical resistance of CW-regenerated protoplasts (Chen, 2020). Similarly, the usefulness of protoplasts for high-throughput RNA sequencing has also been put forward due to its many advantages over traditional RNA-seq. Indeed, protoplasts being single cells, they can give spatiotemporal information on gene dynamic expression in heterogeneous tissues ( $\mathrm{Li}$ et al., 2021).

Protoplasts also provide a facilitated access to the plant $\mathrm{PM}$, and pioneering studies have proven their crucial role in growing biotechnologies such as nanoparticles. These particles have the ability to passively penetrate the PM, but their use in plants is limited due to the presence of the CW (Torney et al., 2007; Liu et al., 2009; Lew et al., 2018). As they are believed to have the potential to overcome current limitations in plant genetic transformation, their effect on plants and their PMs are increasingly studied (Lew et al., 2018). With their easily accessible PM, protoplasts can therefore help understand the fundamental interactions between nanoparticles and plants, as such knowledge is of paramount importance for nanoenabled agriculture. Protoplasts have, for instance, been used to determine the impact of nanopesticides or nanofertilizers, on plant photosynthesis (Wang et al., 2020a). Likewise, protoplast cultures have been used to study gold nanoparticles uptake by plants as their use in industrial areas leads to their release into the environment, which can cause an invisible danger to the ecosystem (Milewska-Hendel et al., 2019). Furthermore, nanoparticles have been previously used to deliver drugs, imaging agents, and DNA for genetic transformation into protoplasts (Torney et al., 2007).

Concomitantly, protoplasts could be valuable plant PM models to study the perception of bioactive molecules such as elicitors by plant cells. Indeed, they could link data obtained by biophysics studies on biomimetic PM models containing representative lipids (Deleu et al., 2014) with the ones provided by biological assays on living plant cells or tissues with complex dynamic PM and CW. Protoplasts-associated technologies and techniques should help improve our fundamental knowledge on plant perception and response to (a)biotic stresses and hence ultimately contribute to develop reliable and efficient solutions for agriculture.

\section{AUTHOR CONTRIBUTIONS}

$\mathrm{GG}, \mathrm{EH}, \mathrm{MD}$, and SD-C designed the outlines of the review and wrote the manuscript with the contribution of SC and MO. All authors contributed to the article and approved the submitted version.

\section{FUNDING}

This work was supported by the National Fund for Scientific Research (FNRS, Belgium), the SFR condorcet (18ARC107), and the "Fondation Universitaire de Belgique" (Belgian University Foundation). GG, was supported by the Foundation for Training in Industrial and Agricultural Research (FRIA, FNRS, grant 1.E.069.20F), and MD and MO are Senior Research Associates of the FNRS. 


\section{REFERENCES}

Anderson, C. T., Carroll, A., Akhmetova, L., and Somerville, C. (2010). Realtime imaging of cellulose reorientation during cell wall expansion in Arabidopsis roots. Plant Physiol. 152, 787-796. doi: 10.1104/pp.109.150128

Aoyagi, H. (2011). Application of plant protoplasts for the production of useful metabolites. Biochem. Eng. J. 56, 1-8. doi: 10.1016/j.bej.2010.05.004

Asai, T., Tena, G., Plotnikova, J., Willmann, M. R., Chiu, W.-L., Gomez-Gomez, L., et al. (2002). MAP kinase signalling cascade in Arabidopsis innate immunity. Nature 415, 977-983. doi: 10.1038/415977a

Babu, M., Griffiths, J. S., Huang, T. S., and Wang, A. (2008). Altered gene expression changes in Arabidopsis leaf tissues and protoplasts in response to plum pox virus infection. BMC Genomics 9:325. doi: 10.1186/1471-2164-9-325

Badaró Costa, N. L., Carvalho, C. R., and Clarindo, W. R. (2018). Improved procedures to assess plant protoplast viability: evidencing cytological and genomic damage. Cytologia 83, 397-405. doi: 10.1508/cytologia.83.397

Barbara, J. B., and Bonner, D. M. (1959). Protoplasts from Neurospora crassa. J. Bacteriol. 78, 550-556. doi: 10.1128/jb.78.4.550-556.1959

Bekesová, S., Komis, G., Krenek, P., Vyplelovà, P., Ovecka, M., Luptovciak, I., et al. (2015). Monitoring protein phosphorylation by acrylamide pendant Phos-tag in various plants. Front. Plant Sci. 6:336. doi: 10.3389/fpls.2015.00336

Bertini, E., Tornielli, G. B., Pezzotti, M., and Zenoni, S. (2019). Regeneration of plants from embryogenic callus-derived protoplasts of Garganega and Sangiovese grapevine (Vitis vinifera L.) cultivars. Plant Cell Tissue Organ Cult. 138, 239-246. doi: 10.1007/s11240-019-01619-1

Bethke, G., Unthan, T., Uhrig, J. F., Pöschl, Y., Gust, A. A., Scheel, D., et al. (2009). Flg22 regulates the release of an ethylene response factor substrate from MAP kinase 6 in Arabidopsis thaliana via ethylene signaling. Proc. Natl. Acad. Sci. U. S. A. 106, 8067-8072. doi: 10.1073/pnas. 0810206106

Bi, G., Zhou, Z., Wang, W., Li, L., Rao, S., Wu, Y., et al. (2018). Receptor-like cytoplasmic kinases directly link diverse pattern recognition receptors to the activation of mitogen-activated protein kinase cascades in Arabidopsis. Plant Cell 30, 1543-1561. doi: 10.1105/tpc.17.00981

Bigeard, J., Colcombet, J., and Hirt, H. (2015). Signaling mechanisms in patterntriggered immunity (PTI). Mol. Plant 8, 521-539. doi: 10.1016/j. molp.2014.12.022

Bigeard, J., and Hirt, H. (2018). Nuclear signaling of plant MAPKs. Front. Plant Sci. 9:469. doi: 10.3389/fpls.2018.00469

Birnbaum, K., Shasha, D. E., Wang, J. Y., Jung, J. W., Lambert, G. M., Galbraith, D. W., et al. (2003). A gene expression map of the Arabidopsis root. Science 302, 1956-1960. doi: 10.1126/science.1090022

Blachutzik, J. O., Demir, F., Kreuzer, I., Hedrich, R., and Harms, G. S. (2012). Methods of staining and visualization of sphingolipid enriched and nonenriched plasma membrane regions of Arabidopsis thaliana with fluorescent dyes and lipid analogues. Plant Methods 8:28. doi: 10.1186/1746-4811-8-28

Bose, J., Pottosin, I. I., Shabala, S. S., Palmgren, M. G., and Shabala, S. (2011). Calcium efflux systems in stress signaling and adaptation in plants. Front. Plant Sci. 2:85. doi: 10.3389/fpls.2011.00085

Böttner, S., Iven, T., Carsjens, C. S., and Dröge-Laser, W. (2009). Nuclear accumulation of the ankyrin repeat protein ANK1 enhances the auxinmediated transcription accomplished by the bZIP transcription factors BZI-1 and BZI-2. Plant J. 58, 914-926. doi: 10.1111/j.1365-313X.2009.03829.x

Boudsocq, M., Barbier-Brygoo, H., and Laurière, C. (2004). Identification of nine sucrose nonfermenting 1-related protein kinases 2 activated by hyperosmotic and saline stresses in Arabidopsis thaliana. J. Biol. Chem. 279, 41758-41766. doi: 10.1074/jbc.M405259200

Boudsocq, M., Willmann, M. R., McCormack, M., Lee, H., Shan, L., He, P., et al. (2010). Differential innate immune signalling via $\mathrm{Ca}^{2+}$ sensor protein kinases. Nature 464, 418-422. doi: 10.1038/nature08794

Carpaneto, A., Ivashikina, N., Levchenko, V., Krol, E., Jeworutzki, E., Zhu, J. K., et al. (2007). Cold transiently activates calcium-permeable channels in Arabidopsis mesophyll cells. Plant Physiol. 143, 487-494. doi: 10.1104/ pp.106.090928

Chan, C., Panzeri, D., Okuma, E., Tõldsepp, K., Wang, Y. Y., Louh, G. Y., et al. (2020). Stress induced factor 2 regulates Arabidopsis stomatal immunity through phosphorylation of the anion channel SLAC1. Plant Cell 32, 2216-2236. doi: $10.1105 /$ tpc. 19.00578
Chen, L. (2020). An impedance-coupled microfluidic device for single-cell analysis of primary cell wall regeneration. Biosens. Bioelectron. 165:112374. doi: 10.1016/j.bios.2020.112374

Chen, D., Cao, Y., Li, H., Kim, D., Ahsan, N., Thelen, J., et al. (2017). Extracellular ATP elicits DORN1-mediated RBOHD phosphorylation to regulate stomatal aperture. Nat. Commun. 8:2265. doi: 10.1038/s41467-017-02340-3

Chen, H., Lai, Z., Shi, J., Xiao, Y., Chen, Z., and Xu, X. (2010). Roles of Arabidopsis WRKY18, WRKY40 and WRKY60 transcription factors in plant responses to abscisic acid and abiotic stress. BMC Plant Biol. 10:281. doi: 10.1186/1471-2229-10-281

Chen, H., Zou, Y., Shang, Y., Lin, H., Wang, Y., Cai, R., et al. (2008). Firefly luciferase complementation imaging assay for protein-protein interactions in plants. Plant Physiol. 146, 368-376. doi: 10.1104/pp.107.111740

Cheng, Z., Li, J. F., Niu, Y., Zhang, X. C., Woody, O. Z., Xiong, Y., et al. (2015). Pathogen-secreted proteases activate a novel plant immune pathway. Nature 521, 213-216. doi: 10.1038/nature14243

Cheng, N., and Nakata, P. A. (2020). Development of a rapid and efficient protoplast isolation and transfection method for chickpea (Cicer arietinum). MethodsX 7:101025. doi: 10.1016/j.mex.2020.101025

Choury, Z., Meschini, R., Dell'Orso, A., Fardusi, M. J., Mugnozza, G. S., and Kuzminsky, E. (2018). Optimized conditions for the isolation of mesophyll protoplasts along the growing season from Arbutus unedo and their use in single cell gel electrophoresis. Plant Cell Tissue Organ Cult. 132, 535-543. doi: 10.1007/s11240-017-1349-6

Cocking, E. C. (1960). A method for the isolation of plant protoplasts and vacuoles. Nature 187, 962-963. doi: 10.1038/187962a0

Cook, D. E., Mesarich, C. H., and Thomma, B. P. H. J. (2015). Understanding plant immunity as a surveillance system to detect invasion. Annu. Rev. Phytopathol. 53, 541-563. doi: 10.1146/annurev-phyto-080614-120114

Couto, D., and Zipfel, C. (2016). Regulation of pattern recognition receptor signalling in plants. Nat. Rev. Immunol. 16, 537-552. doi: 10.1038/nri.2016.77

Cui, Y., Zhang, X., Yu, M., Zhu, Y., Xing, J., and Lin, J. (2019). Techniques for detecting protein-protein interactions in living cells: principles, limitations, and recent progress. Sci. China Life Sci. 62, 619-632. doi: 10.1007/ s11427-018-9500-7

Daněk, M., Angelini, J., Malínská, K., Andrejch, J., Amlerová, Z., Kocourková, D., et al. (2020). Cell wall contributes to the stability of plasma membrane nanodomain organization of Arabidopsis thaliana FLOTILLIN2 and HYPERSENSITIVE INDUCED REACTION1 proteins. Plant J. 101, 619-636. doi: $10.1111 /$ tpj.14566

Daneri-Castro, S. N., and Roberts, T. H. (2016). Isolation of viable protoplasts from the aleurone layers of commercial barley malting varieties. J. Inst. Brew. 122, 693-699. doi: 10.1002/jib.365

daSilva, L. L. P., Taylor, J. P., Hadlington, J. L., Hanton, S. L., Snowden, C. J., Fox, S. J., et al. (2005). Receptor salvage from the prevacuolar compartment is essential for efficient vacuolar protein targeting. Plant Cell 17, 132-148. doi: 10.1105/tpc.104.026351

Davis, H. R., Maddison, A. L., Phillips, D. W., and Jones, H. D. (2020). "Genetic transformation of protoplasts isolated from leaves of Lolium temulentum and Lolium perenne," in Cereal Genomics Methods in Molecular Biology. ed. L. M. Vaschetto (New York, NY: Springer US), 199-205.

Delaunois, B., Farace, G., Jeandet, P., Clément, C., Baillieul, F., Dorey, S., et al. (2014). Elicitors as alternative strategy to pesticides in grapevine? Current knowledge on their mode of action from controlled conditions to vineyard. Environ. Sci. Pollut. Res. 21, 4837-4846. doi: 10.1007/s11356-013-1841-4

Deleu, M., Crowet, J.-M., Nasir, M. N., and Lins, L. (2014). Complementary biophysical tools to investigate lipid specificity in the interaction between bioactive molecules and the plasma membrane: a review. Biochim. Biophys. Acta 1838, 3171-3190. doi: 10.1016/j.bbamem.2014.08.023

Demidchik, V. (2014). Mechanisms and physiological roles of $\mathrm{K}+$ efflux from root cells. J. Plant Physiol. 171, 696-707. doi: 10.1016/j.jplph.2014.01.015

Demidchik, V. (2018). ROS-activated ion channels in plants: biophysical characteristics, physiological functions and molecular nature. Int. J. Mol. Sci. 19:1263. doi: 10.3390/ijms19041263

Demidchik, V., Shabala, S. N., Coutts, K. B., Tester, M. A., and Davies, J. M. (2003). Free oxygen radicals regulate plasma membrane $\mathrm{Ca}^{2+}$ - and $\mathrm{K}^{+}$permeable channels in plant root cells. J. Cell Sci. 116, 81-88. doi: 10.1242/ jcs.00201 
Demidchik, V., Shabala, S. N., and Davies, J. M. (2007). Spatial variation in $\mathrm{H}_{2} \mathrm{O}_{2}$ response of Arabidopsis thaliana root epidermal $\mathrm{Ca}^{2+}$ flux and plasma membrane $\mathrm{Ca}^{2+}$ channels. Plant J. 49, 377-386. doi: 10.1111/j.1365-313X. 2006.02971.x

Demidchik, V., Shang, Z., Shin, R., Thompson, E., Rubio, L., Laohavisit, A., et al. (2009). Plant extracellular ATP signalling by plasma membrane NADPH oxidase and $\mathrm{Ca}^{2+}$ channels. Plant J. 58, 903-913. doi: 10.1111/j.1365-313X. 2009.03830.x

Demidchik, V., Sokolik, A., and Yurin, V. (2006). "Electrophysiological characterization of plant cation channels," in Plant Electrophysiology: Theory and Methods. ed. A. G. Volkov (Berlin, Heidelberg: Springer-Verlag), 173-185.

Denecke, J., Aniento, F., Frigerio, L., Hawes, C., Hwang, I., Mathur, J., et al. (2012). Secretory pathway research: the more experimental systems the better. Plant Cell 24, 1316-1326. doi: 10.1105/tpc.112.096362

Denecke, J., Botterman, J., and Deblaere, R. (1990). Protein secretion in plant cells can occur via a default pathway. Plant Cell 2, 51-59. doi: 10.1105/ tpc.2.1.51

Dröge-Laser, W., Snoek, B. L., Snel, B., and Weiste, C. (2018). The Arabidopsis bZIP transcription factor family - an update. Curr. Opin. Plant Biol. 45, 36-49. doi: 10.1016/j.pbi.2018.05.001

Du, L., and Bao, M. (2005). Plant regeneration from protoplasts isolated from embryogenic suspension cultured cells of Cinnamomum camphora L. Plant Cell Rep. 24, 462-467. doi: 10.1007/s00299-005-0969-1

Dubos, C., Stracke, R., Grotewold, E., Weisshaar, B., Martin, C., and Lepiniec, L. (2010). MYB transcription factors in Arabidopsis. Trends Plant Sci. 15, 573-581. doi: $10.1016 /$ j.tplants.2010.06.005

Eddy, A. A., and Williamson, D. H. (1957). A method of isolating protoplasts from yeast. Nature 179, 1252-1253. doi: 10.1038/1791252a0

Ehlert, A., Weltmeier, F., Wang, X., Mayer, C. S., Smeekens, S., Vicente-Carbajosa, J., et al. (2006). Two-hybrid protein-protein interaction analysis in Arabidopsis protoplasts: establishment of a heterodimerization map of group $\mathrm{C}$ and group S bZIP transcription factors. Plant J. 46, 890-900. doi: 10.1111/j.1365-313X.2006.02731.x

Elzenga, J. T. M. (2012). "Patch clamp techniques for plant cells," in Plant Electrophysiology: Methods and Cell Electrophysiology. ed. A. G. Volkov (Berlin Heidelberg: Springer-Verlag), 225-243.

Engelsdorf, T., Gigli-Bisceglia, N., Veerabagu, M., McKenna, J. F., Vaahtera, L., and Augstein, F. (2018). The plant cell wall integrity maintenance and immune signaling systems cooperate to control stress responses in Arabidopsis thaliana. Sci. Signal. 11:eaao3070. doi: 10.1126/scisignal.aao3070

Faraco, M., di Sansebastiano, G. P., Spelt, K., Koes, R. E., and Quattrocchio, F. M. (2011). One protoplast is not the other! Plant Physiol. 156, 474-478. doi: $10.1104 /$ pp.111.173708

Fliegmann, J., Jauneau, A., Pichereaux, C., Rosenberg, C., Gasciolli, V., Timmers, A. C. J., et al. (2016). LYR3, a high-affinity LCO-binding protein of Medicago truncatula, interacts with LYK3, a key symbiotic receptor. FEBS Lett. 590, 1477-1487. doi: 10.1002/1873-3468.12191

Fowke, L. C., Rennie, P. J., and Constabel, F. (1983). Organelles associated with the plasma membrane of tobacco leaf protoplasts. Plant Cell Rep. 2, 292-295. doi: 10.1007/BF00270184

Fuchs, I., Stölzle, S., Ivashikina, N., and Hedrich, R. (2005). Rice K+ uptake channel OsAKT1 is sensitive to salt stress. Planta 221, 212-221. doi: 10.1007/ s00425-004-1437-9

Fujikawa, Y., and Kato, N. (2007). TECHNICAL ADVANCE: split luciferase complementation assay to study protein-protein interactions in Arabidopsis protoplasts. Plant J. 52, 185-195. doi: 10.1111/j.1365-313X.2007. 03214.x

Gichner, T., Znidar, I., Wagner, E. D., and Plewa, M. J. (2009). "Chapter 4. The use of higher plants in the comet assay," in Issues in Toxicology. eds. A. Dhawan and D. Anderson (Cambridge: Royal Society of Chemistry), 98-119.

Glazebrook, J. (2005). Contrasting mechanisms of defense against biotrophic and necrotrophic pathogens. Annu. Rev. Phytopathol. 43, 205-227. doi: 10.1146/annurev.phyto.43.040204.135923

Gong, B. Q., Guo, J., Zhang, N., Yao, X., Wang, H. B., and Li, J. F. (2019). Cross-microbial protection via priming a conserved immune co-receptor through juxtamembrane phosphorylation in plants. Cell Host Microbe 26, 810-822. doi: 10.1016/j.chom.2019.10.010
Gong, Z., Xiong, L., Shi, H., Yang, S., Herrera-Estrella, L. R., Xu, G., et al. (2020). Plant abiotic stress response and nutrient use efficiency. Sci. China Life Sci. 63, 635-674. doi: 10.1007/s11427-020-1683-x

González-García, M. P., Bustillo-Avendaño, E., Sanchez-Corrionero, A., Del Pozo, J. C., and Moreno-Risueno, M. A. (2020). Fluorescence-activated cell sorting using the D-root device and optimization for scarce and/or nonaccessible root cell populations. Plan. Theory 9:499. doi: 10.3390/plants9040499

Gou, Y.-J., Li, Y.-L., Bi, P.-P., Wang, D.-J., Ma, Y.-Y., Hu, Y., et al. (2020). Optimization of the protoplast transient expression system for gene functional studies in strawberry (Fragaria vesca). Plant Cell Tissue Organ Cult. 141, 41-53. doi: 10.1007/s11240-020-01765-x

Greger, M., Kabir, A. H., Landberg, T., Maity, P. J., and Lindberg, S. (2016). Silicate reduces cadmium uptake into cells of wheat. Environ. Pollut. 211, 90-97. doi: 10.1016/j.envpol.2015.12.027

Gronnier, J., Gerbeau-Pissot, P., Germain, V., Mongrand, S., and Simon-Plas, F. (2018). Divide and rule: plant plasma membrane organization. Trends Plant Sci. 23, 899-917. doi: 10.1016/j.tplants.2018.07.007

Gronnier, J., Germain, V., Gouguet, P., Cacas, J. L., and Mongrand, S. (2016). GIPC: Glycosyl inositol phospho ceramides, the major sphingolipids on earth. Plant Signal. Behav. 11:e1152438. doi: 10.1080/15592324.2016 1152438

Grosjean, K., Der, C., Robert, F., Thomas, D., Mongrand, S., Simon-Plas, F., et al. (2018). Interactions between lipids and proteins are critical for organization of plasma membrane-ordered domains in tobacco BY-2 cells. J. Exp. Bot. 69, 3545-3557. doi: 10.1093/jxb/ery152

Gul, M., Wakeel, A., Steffens, D., and Lindberg, S. (2019). Potassium-induced decrease in cytosolic $\mathrm{Na}^{+}$alleviates deleterious effects of salt stress on wheat (Triticum aestivum L.). Plant Biol. 21, 825-831. doi: 10.1111/plb.12999

Guyon-Debast, A., Alboresi, A., Terret, Z., Charlot, F., Berthier, F., Vendrell-Mir, P., et al. (2021). A blueprint for gene function analysis through base editing in the model plant Physcomitrium (Physcomitrella) patens. New Phytol. 230, 1258-1272. doi: 10.1111/nph.17171

Hahn, F., Korolev, A., Sanjurjo Loures, L., and Nekrasov, V. (2020). A modular cloning toolkit for genome editing in plants. BMC Plant Biol. 20:179. doi: 10.1186/s12870-020-02388-2

Halter, T., Imkampe, J., Mazzotta, S., Wierzba, M., Postel, S., Bücherl, C., et al. (2014). The leucine-rich repeat receptor kinase BIR2 is a negative regulator of BAK1 in plant immunity. Curr. Biol. 24, 134-143. doi: 10.1016/j. cub.2013.11.047

Hamilton, E. S., Schlegel, A. M., and Haswell, E. S. (2015). United in diversity: mechanosensitive ion channels in plants. Annu. Rev. Plant Biol. 66, 113-137. doi: 10.1146/annurev-arplant-043014-114700

Haswell, E. S., Peyronnet, R., Barbier-Brygoo, H., Meyerowitz, E. M., and Frachisse, J.-M. (2008). Two MscS homologs provide mechanosensitive channel activities in the Arabidopsis root. Curr. Biol. 18, 730-734. doi: 10.1016/j. cub.2008.04.039

Hellens, R. P., Allan, A. C., Friel, E. N., Bolitho, K., Grafton, K., Templeton, M. D., et al. (2005). Transient expression vectors for functional genomics, quantification of promoter activity and RNA silencing in plants. Plant Methods 1:13. doi: 10.1186/1746-4811-1-13

Hsu, S.-F., Lai, H.-C., and Jinn, T.-L. (2010). Cytosol-localized heat shock factor-binding protein, AtHSBP, functions as a negative regulator of heat shock response by translocation to the nucleus and is required for seed development in Arabidopsis. Plant Physiol. 153, 773-784. doi: 10.1104/ pp.109.151225

Huby, E., Napier, J. A., Baillieul, F., Michaelson, L. V., and Dhondt-Cordelier, S. (2020). Sphingolipids: towards an integrated view of metabolism during the plant stress response. New Phytol. 225, 659-670. doi: 10.1111/nph.15997

Iven, T., Strathmann, A., Böttner, S., Zwafink, T., Heinekamp, T., Guivarc'h, A., et al. (2010). Homo- and heterodimers of tobacco bZIP proteins counteract as positive or negative regulators of transcription during pollen development. Plant J. 63, 155-166. doi: 10.1111/j.1365-313X.2010.04230.x

Jeworutzki, E., Roelfsema, M. R. G., Anschütz, U., Krol, E., Elzenga, J. T. M., Felix, G., et al. (2010). Early signaling through the Arabidopsis pattern recognition receptors FLS2 and EFR involves $\mathrm{Ca}^{2+}$-associated opening of plasma membrane anion channels. Plant J. 62, 367-378. doi: 10.1111/j.1365313X.2010.04155.X

Jones, J. D. G., and Dangl, J. L. (2006). The plant immune system. Nature 444, 323-329. doi: $10.1038 /$ nature05286 
Kadota, Y., Shirasu, K., and Zipfel, C. (2015). Regulation of the NADPH oxidase RBOHD during plant immunity. Plant Cell Physiol. 56, 1472-1480. doi: $10.1093 / \mathrm{pcp} / \mathrm{pcv} 063$

Kerppola, T. K. (2006). Design and implementation of bimolecular fluorescence complementation (BiFC) assays for the visualization of protein interactions in living cells. Nat. Protoc. 1, 1278-1286. doi: 10.1038/nprot.2006.201

Kinoshita, E., Kinoshita-Kikuta, E., and Koike, T. (2015). Advances in Phostag-based methodologies for separation and detection of the phosphoproteome. Biochim. Biophys. Acta 1854, 601-608. doi: 10.1016/j.bbapap.2014.10.004

Kinoshita, E., Kinoshita-Kikuta, E., Takiyama, K., and Koike, T. (2006). Phosphatebinding tag, a new tool to visualize phosphorylated proteins. Mol. Cell. Proteomics 5, 749-757. doi: 10.1074/mcp.T500024-MCP200

Kinoshita-Kikuta, E., Aoki, Y., Kinoshita, E., and Koike, T. (2007). Label-free kinase profiling using phosphate affinity polyacrylamide gel electrophoresis. Mol. Cell. Proteomics 6, 356-366. doi: 10.1074/mcp.T600044-MCP200

Klymchenko, A. S. (2017). Solvatochromic and fluorogenic dyes as environmentsensitive probes: design and biological applications. Acc. Chem. Res. 50, 366-375. doi: 10.1021/acs.accounts.6b00517

Klymchenko, A. S., and Kreder, R. (2014). Fluorescent probes for lipid rafts: from model membranes to living cells. Chem. Biol. 21, 97-113. doi: 10.1016/j. chembiol.2013.11.009

Kollárová, K., Kusá, Z., Vatehová-Vivodová, Z., and Lišková, D. (2019). The response of maize protoplasts to cadmium stress mitigated by silicon. Ecotoxicol. Environ. Saf. 170, 488-494. doi: 10.1016/j.ecoenv.2018.12.016

Kovtun, Y., Chiu, W. L., Zeng, W., and Sheen, J. (1998). Suppression of auxin signal transduction by a MAPK cascade in higher plants. Nature 395, 716-720. doi: $10.1038 / 27240$

Krzesłowska, M. (2011). The cell wall in plant cell response to trace metals: polysaccharide remodeling and its role in defense strategy. Acta Physiol. Plant. 33, 35-51. doi: 10.1007/s11738-010-0581-z

Kudla, J., and Bock, R. (2016). Lighting the way to protein-protein interactions: recommendations on best practices for bimolecular fluorescence complementation analyses. Plant Cell 28, 1002-1008. doi: 10.1105/tpc.16.00043

Kuki, H., Higaki, T., Yokoyama, R., Kuroha, T., Shinohara, N., Hasezawa, S., et al. (2017). Quantitative confocal imaging method for analyzing cellulose dynamics during cell wall regeneration in Arabidopsis mesophyll protoplasts. Plant Direct 1:e00021. doi: 10.1002/pld3.21

Kuzminsky, E., Meschini, R., Terzoli, S., Pavani, L., Silvestri, C., Choury, Z., et al. (2016). Isolation of mesophyll protoplasts from mediterranean woody plants for the study of DNA integrity under abiotic stress. Front. Plant Sci. 7:1168. doi: $10.3389 /$ fpls.2016.01168

Lamers, J., van der Meer, T., and Testerink, C. (2020). How plants sense and respond to stressful environments. Plant Physiol. 182, 1624-1635. doi: 10.1104/ pp.19.01464

Ledoux, Q., Van Cutsem, P., Markó, I. E., and Veys, P. (2014). Specific localization and measurement of hydrogen peroxide in Arabidopsis thaliana cell suspensions and protoplasts elicited by COS-OGA. Plant Signal. Behav. 9:e28824. doi: $10.4161 /$ psb. 28824

Lee, Y.-S., Mitiku, G., and Endress, A. G. (2001). Short-term effects of Al3+ on the osmotic behavior of red beet (Beta vulgaris L.) protoplasts. Plant Soil 228, 223-232. doi: 10.1023/A:1004886115326

Lenarčič, T., Albert, I., Böhm, H., Hodnik, V., Pirc, K., Zavec, A. B., et al. (2017). Eudicot plant-specific sphingolipids determine host selectivity of microbial NLP cytolysins. Science 358, 1431-1434. doi: 10.1126/science. aan6874

Lew, T. T. S., Wong, M. H., Kwak, S., Sinclair, R., Koman, V. B., and Strano, M. S. (2018). Rational design principles for the transport and subcellular distribution of nanomaterials into plant protoplasts. Small 14:1802086. doi: 10.1002/ smll.201802086

Li, Z., Ao, Y., Feng, D., Liu, J., Wang, J., Wang, H. B., et al. (2017). OsRLCK 57, OsRLCK107 and OsRLCK118 positively regulate chitin- and PGN-induced immunity in rice. Rice 10:6. doi: 10.1186/s12284-017-0145-6

Li, J.-F., Bush, J., Xiong, Y., Li, L., and McCormack, M. (2011). Large-scale protein-protein interaction analysis in Arabidopsis mesophyll protoplasts by split firefly luciferase complementation. PLoS One 6:e27364. doi: 10.1371/ journal.pone. 0027364

Li, H., Dai, X., Huang, X., Xu, M., Wang, Q., Yan, X., et al. (2021). Single-cell RNA sequencing reveals a high-resolution cell atlas of xylem in Populus. J. Integr. Plant Biol. doi: 10.1111/jipb.13159
Li, B., Ferreira, M. A., Huang, M., Camargos, L. F., Yu, X., Teixeira, R. M., et al. (2019). The receptor-like kinase NIK1 targets FLS2/BAK1 immune complex and inversely modulates antiviral and antibacterial immunity. Nat. Commun. 10:4996. doi: 10.1038/s41467-019-12847-6

Li, M., Sun, X., Di, D., Zhang, A., Qing, L., Zhou, T., et al. (2020). Maize AKIN $\beta \gamma$ proteins interact with P8 of rice black streaked dwarf virus and inhibit viral infection. Viruses 12:1387. doi: 10.3390/v12121387

Li, J. F., Zhang, D., and Sheen, J. (2014). Epitope-tagged protein-based artificial miRNA screens for optimized gene silencing in plants. Nat. Protoc. 9, 939-949. doi: 10.1038/nprot.2014.061

Lim, G. H., Singhal, R., Kachroo, A., and Kachroo, P. (2017). Fatty acid- and lipid-mediated signaling in plant defense. Annu. Rev. Phytopathol. 55, 505-536. doi: 10.1146/annurev-phyto-080516-035406

Lin, H. Y., Chen, J. C., and Fang, S. C. (2018). A protoplast transient expression system to enable molecular, cellular, and functional studies in phalaenopsis orchids. Front. Plant Sci. 9:843. doi: 10.3389/fpls.2018.00843

Lin, Y.-C., Li, W., Chen, H., Li, Q., Sun, Y.-H., Shi, R., et al. (2014). A simple improved-throughput xylem protoplast system for studying wood formation. Nat. Protoc. 9, 2194-2205. doi: 10.1038/nprot.2014.147

Liu, Q., Chen, B., Wang, Q., Shi, X., Xiao, Z., Lin, J., et al. (2009). Carbon nanotubes as molecular transporters for walled plant cells. Nano Lett. 9, 1007-1010. doi: 10.1021/nl803083u

Liu, Z., Jia, Y., Ding, Y., Shi, Y., Li, Z., Guo, Y., et al. (2017). Plasma membrane CRPK1-mediated phosphorylation of 14-3-3 proteins induces their nuclear import to fine-tune CBF signaling during cold response. Mol. Cell 66, 117. e5-128.e5. doi: 10.1016/j.molcel.2017.02.016

Liu, C., Ou, S., Mao, B., Tang, J., Wang, W., Wang, H., et al. (2018). Early selection of bZIP73 facilitated adaptation of japonica rice to cold climates. Nat. Commun. 9:3302. doi: 10.1038/s41467-018-05753-w

Liya, M., Huan, Z., Lirong, S., Yiheng, J., Guozeng, Z., Chen, M., et al. (2012). $\mathrm{NADPH}$ oxidase AtrbohD and AtrbohF function in ROS-dependent regulation of $\mathrm{Na}^{+} / \mathrm{K}^{+}$homeostasis in Arabidopsis under salt stress. J. Exp. Bot. 63, 305-317. doi: $10.1093 /$ jxb/err280

Long, Y., Stahl, Y., Weidtkamp-Peters, S., Smet, W., Du, Y., Gadella, T. W. J. J., et al. (2018). Optimizing FRET-FLIM labeling conditions to detect nuclear protein interactions at native expression levels in living Arabidopsis roots. Front. Plant Sci. 9:639. doi: 10.3389/fpls.2018.00639

Ma, X., Claus, L. A. N., Leslie, M. E., Tao, K., Wu, Z., Liu, J., et al. (2020). Ligand-induced monoubiquitination of BIK1 regulates plant immunity. Nature 581, 199-203. doi: 10.1038/s41586-020-2210-3

Maintz, J., Cavdar, M., Tamborski, J., Kwaaitaal, M., Huisman, R., Meesters, C. et al. (2014). Comparative analysis of MAMP-induced calcium influx in Arabidopsis seedlings and protoplasts. Plant Cell Physiol. 55, 1813-1825. doi: $10.1093 / \mathrm{pcp} / \mathrm{pcu} 112$

Malinovsky, F. G. (2014). The role of the cell wall in plant immunity. Front. Plant Sci. 5:178. doi: 10.3389/fpls.2014.00178

Mamode Cassim, A., Gouguet, P., Gronnier, J., Laurent, N., Germain, V., Grison, M., et al. (2019). Plant lipids: key players of plasma membrane organization and function. Prog. Lipid Res. 73, 1-27. doi: 10.1016/j. plipres.2018.11.002

Martinière, A., Lavagi, I., Nageswaran, G., Rolfe, D. J., Maneta-Peyret, L., Luu, D. T., et al. (2012). Cell wall constrains lateral diffusion of plant plasma-membrane proteins. Proc. Natl. Acad. Sci. U. S. A. 109, 12805-12810. doi: $10.1073 /$ pnas. 1202040109

Menzel, W., Stenzel, I., Helbig, L., Krishnamoorthy, P., Neumann, S., Eschen-Lippold, L., et al. (2019). A PAMP-triggered MAPK cascade inhibits phosphatidylinositol 4,5-bisphosphate production by PIP5K6 in Arabidopsis thaliana. New Phytol. 224, 833-847. doi: 10.1111/nph.16069

Miao, Y., and Jiang, L. (2007). Transient expression of fluorescent fusion proteins in protoplasts of suspension cultured cells. Nat. Protoc. 2, 2348-2353. doi: $10.1038 /$ nprot.2007.360

Milewska-Hendel, A., Zubko, M., Stróż, D., and Kurczyńska, E. (2019). Effect of nanoparticles surface charge on the Arabidopsis thaliana (L.) roots development and their movement into the root cells and protoplasts. Int J. Mol. Sci. 20:1650. doi: 10.3390/ijms20071650

Moon, S.-J., Min, M. K., Kim, J.-A., Kim, D. Y., Yoon, I. S., Kwon, T. R., et al. (2019). Ectopic expression of OsDREB1G, a member of the OsDREB1 subfamily, confers cold stress tolerance in rice. Front. Plant Sci. 10:297. doi: $10.3389 /$ fpls.2019.00297 
Mueller, K., Bittel, P., Chinchill, D., Jehle, A. K., Albert, M., Boller, T., et al. (2012). Chimeric FLS2 receptors reveal the basis for differential flagellin perception in Arabidopsis and tomato. Plant Cell 24, 2213-2224. doi: 10.1105/ tpc.112.096073

Nagano, M., Ishikawa, T., Fujiwara, M., Fukao, Y., Kawano, Y., Kawai-Yamada, M., et al. (2016). Plasma membrane microdomains are essential for RaclRbohB/H-mediated immunity in rice. Plant Cell 28, 1966-1983. doi: 10.1105/ tpc.16.00201

Nakagawa, Y., Katagiri, T., Shinozaki, K., Qi, Z., Tatsumi, H., Furuichi, T., et al. (2007). Arabidopsis plasma membrane protein crucial for $\mathrm{Ca}^{2+}$ influx and touch sensing in roots. Proc. Natl. Acad. Sci. U. S. A. 104, 3639-3944. doi: $10.1073 /$ pnas.0607703104

Neelakandan, A. K., and Wang, K. (2012). Recent progress in the understanding of tissue culture-induced genome level changes in plants and potential applications. Plant Cell Rep. 31, 597-620. doi: 10.1007/s00299-011-1202-Z

Nelson, B. K., Cai, X., and Nebenführ, A. (2007). A multicolored set of in vivo organelle markers for co-localization studies in Arabidopsis and other plants. Plant J. 51, 1126-1136. doi: 10.1111/j.1365-313X.2007.03212.x

Nicolia, A., Fält, A.-S., Hofvander, P., and Handersson, M. (2021). "Protoplastbased method for genome editing in tetraploid potato," in Crop Breeding: Genetic Improvement Methods in Molecular Biology. ed. Tripodi (New York, NY: Springer US), 177-186.

Park, W., Kim, H.-S., Park, T.-W., Lee, Y.-H., and Ahn, S.-J. (2017). Functional characterization of plasma membrane-localized organic acid transporter (CsALMT1) involved in aluminum tolerance in Camelina sativa L. Plant Biotechnol. Rep. 11, 181-192. doi: 10.1007/s11816-017-0441-Z

Pasternak, T., Lystvan, K., Betekhtin, A., and Hasterok, R. (2020). From single cell to plants: mesophyll protoplasts as a versatile system for investigating plant cell reprogramming. Int. J. Mol. Sci. 21:4195. doi: 10.3390/ijms21124195

Pecher, P., Eschen-Lippold, L., Herklotz, S., Kuhle, K., Naumann, K., Bethke, G., et al. (2014). The Arabidopsis thaliana mitogen-activated protein kinases MPK3 and MPK6 target a subclass of 'VQ-motif'-containing proteins to regulate immune responses. New Phytol. 203, 592-606. doi: 10.1111/nph.12817

Petropoulou, Y., Manetas, Y., and Gavalas, N. A. (1990). Intact mesophyll protoplasts from Zea mays as a source of phosphoenolpyruvate carboxylase unaffected by extraction: advantages and limitations. Physiol. Plant. 80, 605-611. doi: 10.1111/j.1399-3054.1990.tb05685.x

Pham, A. Q., Cho, S.-H., Nguyen, C. T., and Stacey, G. (2020). Arabidopsis lectin receptor kinase $\mathrm{P} 2 \mathrm{~K} 2$ is a second plant receptor for extracellular ATP and contributes to innate immunity. Plant Physiol. 183, 1364-1375. doi: 10.1104/pp.19.01265

Poot-Poot, W., Rodas-Junco, B. A., Muñoz-Sánchez, J. A., and Hernández-Sotomayor, S. M. T. (2016). Protoplasts: a friendly tool to study aluminum toxicity and coffee cell viability. Springerplus 5:1452. doi: 10.1186/ s40064-016-3140-2

Qiu, L., Wang, Y., and Qu, H. (2020). Loading calcium fluorescent probes into protoplasts to detect calcium in the flesh tissue cells of Malus domestica. Hortic. Res. 7:91. doi: 10.1038/s41438-020-0315-3

Ramon, M., Dang, T. V. T., Broeckx, T., Hulsmans, S., Crepin, N., Sheen, J., et al. (2019). Default activation and nuclear translocation of the plant cellular energy sensor snrk1 regulate metabolic stress responses and development. Plant Cell 31, 1614-1632. doi: 10.1105/tpc.18.00500

Rios, A. F., Radoeva, T., De Rybel, B., Weijers, D., and Borst, J. W. (2017). "FRET-FLIM for visualizing and quantifying protein interactions in live plant cells," in Plant Hormones: Methods and Protocols. Methods in Molecular Biology. Vol. 1497. eds. J. Kleine-Vehn and M. Sauer (New York, NY: Springer), 135-146.

Saijo, Y., and Loo, E. P. (2020). Plant immunity in signal integration between biotic and abiotic stress responses. New Phytol. 225, 87-104. doi: 10.1111/nph.15989

Sakai, K., Charlot, F., Le Saux, T., Bonhomme, S., Nogué, F., Palauqui, J.-C., et al. (2019). Design of a comprehensive microfluidic and microscopic toolbox for the ultra-wide spatio-temporal study of plant protoplasts development and physiology. Plant Methods 15:79. doi: 10.1186/s13007-019-0459-z

Sangra, A., Shahin, L., and Dhir, S. K. (2019). Optimization of isolation and culture of protoplasts in alfalfa (Medicago sativa) cultivar Regen-SY. Am. J. Plant Sci. 10, 1206-1219. doi: 10.4236/ajps.2019.107086

Santos, C. L. V., Pourrut, B., and Ferreira de Oliveira, J. M. P. (2015). The use of comet assay in plant toxicology: recent advances. Front. Genet. 6:216. doi: $10.3389 /$ fgene. 2015.00216
Saur, I. M. L., Bauer, S., Lu, X., and Schulze-Lefert, P. (2019). A cell death assay in barley and wheat protoplasts for identification and validation of matching pathogen AVR effector and plant NLR immune receptors. Plant Methods 15:118. doi: 10.1186/s13007-019-0502-0

Schellenberger, R., Touchard, M., Clément, C., Baillieul, F., Cordelier, S., Crouzet, J., et al. (2019). Apoplastic invasion patterns triggering plant immunity: plasma membrane sensing at the frontline. Mol. Plant Pathol. 20, 1602-1616. doi: 10.1111/mpp.12857

Shan, X., Li, Y., Zhou, L., Tong, L., Wei, C., Qiu, L., et al. (2019). Efficient isolation of protoplasts from freesia callus and its application in transient expression assays. Plant Cell Tissue Organ Cult. 138, 529-541. doi: 10.1007/ s11240-019-01649-9

Sharma, M., Bennewitz, B., and Klösgen, R. B. (2018). Dual or not dual? comparative analysis of fluorescence microscopy-based approaches to study organelle targeting specificity of nuclear-encoded plant proteins. Front. Plant Sci. 9:1350. doi: 10.3389/fpls.2018.01350

Shaw, R., Tian, X., and Xu, J. (2021). Single-cell transcriptome analysis in plants: advances and challenges. Mol. Plant 14, 115-126. doi: 10.1016/j. molp.2020.10.012

Sheen, J. (2001). Signal transduction in maize and Arabidopsis mesophyll protoplasts. Plant Physiol. 127, 1466-1475. doi: 10.1104/pp.010820

Sheikh, A. H., Eschen-Lippold, L., Pecher, P., Hoehenwarter, W., Sinha, A. K., Scheel, D., et al. (2016). Regulation of WRKY46 transcription factor function by mitogen-activated protein kinases in Arabidopsis thaliana. Front. Plant Sci. 7:61. doi: 10.3389/fpls.2016.00061

Shen, J., Suen, P. K., Wang, X., Lin, Y., Lo, S. W., Rojo, E., et al. (2013). An in vivo expression system for the identification of cargo proteins of vacuolar sorting receptors in Arabidopsis culture cells. Plant J. 75, 1003-1017. doi: $10.1111 /$ tpj. 12257

Souza, C. d. A., Li, S., Lin, A. Z., Boutrot, F., Grossmann, G., Zipfel, C., et al. (2020). Cellulose-derived oligomers act as damage-associated molecular patterns and trigger defense-like responses. Plant Physiol. 173, 2383-2398. doi: $10.1104 / \mathrm{pp} .16 .01680$

Struk, S., Jacobs, A., Martín-Fontecha, E. S., Gevaert, K., Cubas, P., and Goormachtig, S. (2019). Exploring the protein-protein interaction landscape in plants. Plant Cell Environ. 42, 387-409. doi: 10.1111/pce.13433

Sze, H., and Chanroj, S. (2018). Plant endomembrane dynamics: studies of $\mathrm{K}+/ \mathrm{H}+$ antiporters provide insights on the effects of $\mathrm{pH}$ and ion homeostasis. Plant Physiol. 177, 875-895. doi: 10.1104/pp.18.00142

Tagawa, S., and Kondo, T. (2018). Secretion of a callose hollow fiber from herbaceous plant protoplasts induced by inhibition of cell wall formation. J. Wood Sci. 64, 467-476. doi: 10.1007/s10086-018-1726-8

Tagawa, S., Yamagishi, Y., Watanabe, U., Funada, R., and Kondo, T. (2019). Dynamics of structural polysaccharides deposition on the plasma-membrane surface of plant protoplasts during cell wall regeneration. J. Wood Sci. 65:47. doi: 10.1186/s10086-019-1826-0

Takahashi, Y., Zhang, J., Hsu, P. K., Ceciliato, P. H. O., Zhang, L., Dubeaux, G., et al. (2020). MAP3Kinase-dependent SnRK2-kinase activation is required for abscisic acid signal transduction and rapid osmotic stress response. Nat. Commun. 11:12. doi: 10.1038/s41467-019-13875-y

Takai, R., Kaneda, T., Isogai, A., Takayama, S., and Che, F. S. (2007). A new method of defense response analysis using a transient expression system in rice protoplasts. Biosci. Biotechnol. Biochem. 71, 590-593. doi: 10.1271/ bbb. 60526

Thévenin, J., Dubos, C., Xu, W., Gourrierec, J. L., Kelemen, Z., Charlot, F., et al. (2012). A new system for fast and quantitative analysis of heterologous gene expression in plants. New Phytol. 193, 504-512. doi: 10.1111/j.1469-8137.2011.03936.x

Tian, W., Hou, C., Ren, Z., Wang, C., Zhao, F., Dahlbeck, D., et al. (2019). A calmodulin-gated calcium channel links pathogen patterns to plant immunity. Nature 572, 131-135. doi: 10.1038/s41586-019-1413-y

Torney, F., Trewyn, B. G., Lin, V. S.-Y., and Wang, K. (2007). Mesoporous silica nanoparticles deliver DNA and chemicals into plants. Nat. Nanotechnol. 2, 295-300. doi: 10.1038/nnano.2007.108

Tripathi, D., Nam, A., Oldenburg, D. J., and Bendich, A. J. (2020). Reactive oxygen species, antioxidant agents, and DNA damage in developing maize mitochondria and plastids. Front. Plant Sci. 11:596. doi: 10.3389/fpls.2020.00596

Underwood, W., Ryan, A., and Somerville, S. C. (2017). An Arabidopsis lipid flippase is required for timely recruitment of defenses to the host-pathogen 
interface at the plant cell surface. Mol. Plant 10, 805-820. doi: 10.1016/j. molp.2017.04.003

Wang, X., Feng, C., Tian, L., Hou, C., Tian, W., Hu, B., et al. (2021). A transceptor-channel complex couples nitrate sensing to calcium signaling in Arabidopsis. Mol. Plant 14, 774-786. doi: 10.1016/j.molp.2021.02.005

Wang, A., Jin, Q., Xu, X., Miao, A., White, J. C., Gardea-Torresdey, J. L., et al. (2020a). High-throughput screening for engineered nanoparticles that enhance photosynthesis using mesophyll protoplasts. J. Agric. Food Chem. 68, 3382-3389. doi: 10.1021 acs.jafc.9b06429

Wang, F., Jing, W., and Zhang, W. (2014). The mitogen-activated protein kinase cascade MKK1-MPK4 mediates salt signaling in rice. Plant Sci. 227, 181-189. doi: 10.1016/j.plantsci.2014.08.007

Wang, F.-Z., Zhang, N., Guo, Y.-J., Gong, B.-Q., and Li, J.-F. (2020b). Split Nano luciferase complementation for probing protein-protein interactions in plant cells. J. Integr. Plant Biol. 62, 1065-1079. doi: 10.1111/jipb.12891

Wani, S. H., Anand, S., Singh, B., Bohra, A., and Joshi, R. (2021). WRKY transcription factors and plant defense responses: latest discoveries and future prospects. Plant Cell Rep. 40, 1071-1085. doi: 10.1007/s00299-021-02691-8

Watanabe, M., Setoguchi, D., Uehara, K., Ohtsuka, W., and Watanabe, Y. (2002). Apoptosis-like cell death of Brassica napus leaf protoplasts. New Phytol. 156, 417-426. doi: 10.1046/j.1469-8137.2000.00536.x

Wehner, N., Hartmann, L., Ehlert, A., Böttner, S., Oñate-Sánchez, L., and Dröge-Laser, W. (2011). High-throughput protoplast transactivation (PTA) system for the analysis of Arabidopsis transcription factor function. Plant J. 68, 560-569. doi: 10.1111/j.1365-313X.2011.04704.x

Weibull, C. (1953). The isolation of protoplasts from bacillus megaterium by controlled treatment with lysozyme. J. Bacteriol. 66, 688-695. doi: 10.1128/ jb.66.6.688-695.1953

Wu, F., Chi, Y., Jiang, Z., Xu, Y., Xie, L., Huang, F., et al. (2020a). Hydrogen peroxide sensor HPCA1 is an LRR receptor kinase in Arabidopsis. Nature 578, 577-581. doi: 10.1038/s41586-020-2032-3

Wu, H. Y., Liu, K. H., Wang, Y. C., Wu, J. F., Chiu, W. L., Chen, C. Y., et al. (2014a). AGROBEST: an efficient agrobacterium-mediated transient expression method for versatile gene function analyses in Arabidopsis seedlings. Plant Methods 10:19. doi: 10.1186/1746-4811-10-19

Wu, S., Shan, L., and He, P. (2014b). Microbial signature-triggered plant defense responses and early signaling mechanisms. Plant Sci. 228, 118-126. doi: 10.1016/j.plantsci.2014.03.001

Wu, S., Zhu, H., Liu, J., Yang, Q., Shao, X., Bi, F., et al. (2020b). Establishment of a PEG-mediated protoplast transformation system based on DNA and CRISPR/Cas9 ribonucleoprotein complexes for banana. BMC Plant Biol. 20:425. doi: 10.1186/s12870-020-02609-8

Xing, T., and Wang, X. (2015). Protoplasts in plant signaling analysis: moving forward in the omics era. Botany 93, 325-332. doi: 10.1139/cjb-2014-0219

Yang, J., Liu, S., Ji, L., Tang, X., Zhu, Y., and Xie, G. (2020). Identification of novel OsCML16 target proteins and differential expression analysis under abiotic stresses in rice. J. Plant Physiol. 249:153165. doi: 10.1016/j. jplph.2020.153165

Ye, K., Li, H., Ding, Y., Shi, Y., Song, C., Gong, Z., et al. (2019). BRASSINOSTEROID-INSENSITIVE2 negatively regulates the stability of transcription factor ICE1 in response to cold stress in Arabidopsis. Plant Cell 31, 2682-2696. doi: 10.1105/tpc. 19.00058

Yeh, Y.-H., Chang, Y.-H., Huang, P.-Y., Huang, J.-B., and Zimmerli, L. (2015). Enhanced Arabidopsis pattern-triggered immunity by overexpression of cysteine-rich receptor-like kinases. Front. Plant Sci. 6:322. doi: 10.3389/ fpls.2015.00322

Yekondi, S., Liang, F.-C., Okuma, E., Radziejwoski, A., Mai, H.-W., Swain, S., et al. (2018). Nonredundant functions of Arabidopsis LecRK-V.2 and LecRKVII.1 in controlling stomatal immunity and jasmonate-mediated stomatal closure. New Phytol. 218, 253-268. doi: 10.1111/nph.14953

Yemelyanov, V. V., Chirkova, T. V., Shishova, M. F., and Lindberg, S. M. (2020). Potassium efflux and cytosol acidification as primary anoxia-induced events in wheat and rice seedlings. Plan. Theory 9:1216. doi: 10.3390/plants9091216

Yokoyama, R., Kuki, H., Kuroha, T., and Nishitani, K. (2016). Arabidopsis regenerating protoplast: a powerful model system for combining the proteomics of cellwall proteins and the visualization of cell wall dynamics. Proteomes 4:34. doi: 10.3390/proteomes4040034

Yoo, S. D., Cho, Y. H., and Sheen, J. (2007). Arabidopsis mesophyll protoplasts: a versatile cell system for transient gene expression analysis. Nat. Protoc. 2, 1565-1572. doi: 10.1038/nprot.2007.199

Yoshioka, K., and Moeder, W. (2020). Calcium channel helps shut the door on intruders. Nature 585, 507-508. doi: 10.1038/d41586-020-02504-0

Yu, X., Feng, B., He, P., and Shan, L. (2017). From chaos to harmony: responses and signaling upon microbial pattern recognition. Annu. Rev. Phytopathol. 55, 109-137. doi: 10.1146/annurev-phyto-080516-035649

Yu, X., Xu, G., Li, B., de Souza Vespoli, L., Liu, H., Moeder, W., et al. (2019). The receptor kinases BAK1/SERK4 regulate $\mathrm{Ca}^{2+}$ channel-mediated cellular homeostasis for cell death containment. Curr. Biol. 29, 3778.e8-3790.e8. doi: 10.1016/j.cub.2019.09.018

Yu, Y., Yu, P.-C., Chang, W.-J., Yu, K., and Lin, C.-S. (2020). Plastid transformation: how does it work? Can it be applied to crops? What can it offer? Int. J. Mol. Sci. 21:4854. doi: 10.3390/ijms21144854

Zhang, M., Hu, S., Yi, F., Gao, Y., Zhu, D., Wang, Y., et al. (2021). Organelle visualization with multicolored fluorescent markers in bamboo. Front. Plant Sci. 12:552. doi: 10.3389/fpls.2021.658836

Zhang, Q.-F., Li, J., Bi, F.-C., Liu, Z., Chang, Z.-Y., Wang, L.-Y., et al. (2020). Ceramide-induced cell death depends on calcium and caspase-like activity in rice. Front. Plant Sci. 11:145. doi: 10.3389/fpls.2020.00145

Zhang, X., Wang, L., He, C., and Luo, H. (2016). An efficient transient mesophyll protoplast system for investigation of the innate immunity responses in the rubber tree (Hevea brasiliensis). Plant Cell Tissue Organ Cult. 126, 281-290. doi: 10.1007/s11240-016-0997-2

Zhao, C., Randall, D., Holford, P., Haigh, A. M., and Chen, Z. H. (2019). Isolation of high purity guard cell protoplasts of Arabidopsis thaliana for omics research. Plant Growth Regul. 89, 37-47. doi: 10.1007/s10725-01900520-3

Zheng, X., Kang, S., Jing, Y., Ren, Z., Li, L., Zhou, J. M., et al. (2018). Dangerassociated peptides close stomata by OST1-independent activation of anion channels in guard cells. Plant Cell 30, 1132-1146. doi: 10.1105/tpc.17.00701

Zhou, Q., Jiang, Z., Li, Y., Zhang, T., Zhu, H., Zhao, F., et al. (2019). Mesophyll protoplast isolation technique and flow cytometry analysis of ancient Platycladus orientalis (Cupressaceae). Turk. J. Agric. For. 43, 275-287. doi: 10.3906/ $\operatorname{tar}-1805-62$

Zhou, J., and Zhang, Y. (2020). Plant immunity: danger perception and signaling. Cell 181, 978-989. doi: 10.1016/j.cell.2020.04.028

Zhu, J. (2016). Review abiotic stress signaling and responses in plants. Cell 167, 313-324. doi: 10.1016/j.cell.2016.08.029

Zhu, D., Zhang, M., Gao, C., and Shen, J. (2020). Protein trafficking in plant cells: tools and markers. Sci. China Life Sci. 63, 343-363. doi: 10.1007/ s11427-019-9598-3

Zipfel, C., and Oldroyd, G. E. D. (2017). Plant signalling in symbiosis and immunity. Nature 543, 328-336. doi: 10.1038/nature22009

Conflict of Interest: The authors declare that the research was conducted in the absence of any commercial or financial relationships that could be construed as a potential conflict of interest.

Publisher's Note: All claims expressed in this article are solely those of the authors and do not necessarily represent those of their affiliated organizations, or those of the publisher, the editors and the reviewers. Any product that may be evaluated in this article, or claim that may be made by its manufacturer, is not guaranteed or endorsed by the publisher.

Copyright $\odot 2021$ Gilliard, Huby, Cordelier, Ongena, Dhondt-Cordelier and Deleu. This is an open-access article distributed under the terms of the Creative Commons Attribution License (CC BY). The use, distribution or reproduction in other forums is permitted, provided the original author(s) and the copyright owner(s) are credited and that the original publication in this journal is cited, in accordance with accepted academic practice. No use, distribution or reproduction is permitted which does not comply with these terms. 